\title{
Effects of Origanum vulgare essential oil and its two main components, carvacrol and thymol, on the plant pathogen Botrytis cinerea
}

\author{
Huiyu Hou ${ }^{\text {Equal first author, 1, } 2}$, Xueying Zhang ${ }^{1,2}$, Te Zhao ${ }^{\text {Corresp., 1, } 2}$, Lin Zhou ${ }^{\text {Corresp. Equal first author, } 1,2}$ \\ ${ }^{1}$ Henan Key Laboratory for Creation and Application of New Pesticides, zhengzhou, Henan, China \\ College of Plant Protection, Henan Agricultural University, zhengzhou, Henan, China \\ Corresponding Authors: Te Zhao, Lin Zhou \\ Email address: tezhao@126.com, zhoulinhenau@163.com
}

Background: Botrytis cinerea causes serious gray mold disease in many plants. This pathogen has developed resistance to many fungicides. Thus, it has become necessary to look for new safe yet effective compounds against $B$. cinerea.

Methods: Essential oils (EOs) from 17 plant species were assayed against $B$. cinerea, of which Origanum vulgare essential oil (OVEO) showed strong antifungal activity, and accordingly its main components were detected by GC/MS. Further study was conducted on the effects of OVEO, carvacrol and thymol in vitro on mycelium growth and spore germination, mycelium morphology, leakages of cytoplasmic contents, mitochondrial injury and accumulation of reactive oxygen species (ROS) of $B$. cinerea. The control efficacies of OVEO, carvacrol and thymol on tomato grey mould were evaluated in vivo.

Results: Of all the 17 plant EOs tested, Cinnamomum cassia, Litsea cubeba var. formosana and $O$. vulgare essential oils had the best inhibitory effect on $B$. cinerea, with $0.5 \mathrm{mg} / \mathrm{mL}$ completely inhibiting the mycelium growth of $B$. cinerea. Twenty-one different compounds of OVEO were identified by gas chromatography-mass spectrometry, and the main chemical components were carvacrol (89.98\%), $\beta$ caryophyllene (3.34\%), thymol (2.39\%), $\alpha$-humulene (1.38\%) and 1-methyl-2-propan-2-ylbenzene isopropyl benzene (1.36\%). In vitro experiment showed $\mathrm{EC}_{50}$ values of OVEO, carvacrol and thymol were 140.04, 9.09 and $21.32 \mu \mathrm{g} / \mathrm{mL}$, respectively. Carvacrol and thymol completely inhibited the spore germination of $B$. cinerea at the concentration of $300 \mu \mathrm{g} / \mathrm{mL}$ while the inhibition rate of OVEO was $80.03 \%$. $\mathrm{EC}_{50}$ of carvacrol and thymol have significantly $(P<0.05)$ reduced the fresh and dry weight of mycelia. The collapse and damage on $B$. cinerea mycelia treated with $40 \mu \mathrm{g} / \mathrm{mL}$ of carvacrol and thymol was examined by scanning electron microscope (SEM). Through extracellular conductivity test and fluorescence microscope observation, it was found that carvacrol and thymol led to increase the permeability of target cells, the destruction of mitochondrial membrane and ROS accumulation. In vivo conditions, $1000 \mu \mathrm{g} / \mathrm{mL}$ carvacrol had the best protective and therapeutic effects on tomato gray mold (77.98\% and $28.04 \%$, respectively), and the protective effect was significantly higher than that of $400 \mu \mathrm{g} / \mathrm{mL}$ pyrimethanil (43.15\%). While the therapeutic and protective effects of $1000 \mu \mathrm{g} / \mathrm{mL} \mathrm{O}$. vulgare essential and thymol were comparable to agent control.

Conclusions: OVEO showed moderate antifungal activity, whereas its main components carvacrol and thymol have great application potential as natural fungicides or lead compounds for commercial fungicides in preventing and controlling plant diseases caused by $B$. cinerea . 
1 Effects of Origanum vulgare essential oil and its two main components, carvacrol and thymol, on the plant pathogen Botrytis cinerea

Huiyu Hou ${ }^{1,2} \quad$ Xueying Zhang ${ }^{1,2} \quad$ Te Zhao $^{1,2 *} \quad$ Lin Zhou ${ }^{1,2}$ *

${ }^{1}$ Henan Key Laboratory for Creation and Application of New Pesticides, Zhengzhou 450002, P.R.China

${ }^{2}$ College of Plant Protection, Henan Agricultural University, Zhengzhou 45000, P.R.China

E-mail: zhoulinhenau@163.com, tezhao@126.com.

$9 *$ indicates the authors who contributed equally to this study.

1 Abstract

11 Background: Botrytis cinerea causes serious gray mold disease in many plants. This pathogen has developed resistance to many fungicides. Thus, it has become necessary to look for new safe yet effective compounds against B. cinerea.

1 Methods: Essential oils (EOs) from 17 plant species were assayed against $B$. cinerea, of which 1 Origanum vulgare essential oil (OVEO) showed strong antifungal activity, and accordingly its 1 main components were detected by GC/MS. Further study was conducted on the effects of 1 OVEO, carvacrol and thymol in vitro on mycelium growth and spore germination, mycelium 1 morphology, leakages of cytoplasmic contents, mitochondrial injury and accumulation of

19 reactive oxygen species (ROS) of $B$. cinerea. The control efficacies of OVEO, carvacrol and thymol on tomato grey mould were evaluated in vivo.

1 Results: Of all the 17 plant EOs tested, Cinnamomum cassia, Litsea cubeba var. formosana and $O$. vulgare essential oils had the best inhibitory effect on $B$. cinerea, with $0.5 \mathrm{mg} / \mathrm{mL}$ completely inhibiting the mycelium growth of $B$. cinerea. Twenty-one different compounds of OVEO were identified by gas chromatography-mass spectrometry, and the main chemical components were carvacrol (89.98\%), $\beta$-caryophyllene (3.34\%), thymol (2.39\%), $\alpha$-humulene (1.38\%) and 1 methyl-2-propan-2-ylbenzene isopropyl benzene (1.36\%). In vitro experiment showed $\mathrm{EC}_{50}$ 
values of OVEO, carvacrol and thymol were 140.04, 9.09 and $21.32 \mu \mathrm{g} / \mathrm{mL}$, respectively. Carvacrol and thymol completely inhibited the spore germination of $B$. cinerea at the 9 concentration of $300 \mu \mathrm{g} / \mathrm{mL}$ while the inhibition rate of OVEO was $80.03 \%$. $\mathrm{EC}_{50}$ of carvacrol and thymol have significantly $(P<0.05)$ reduced the fresh and dry weight of mycelia. The collapse and damage on $B$. cinerea mycelia treated with $40 \mu \mathrm{g} / \mathrm{mL}$ of carvacrol and thymol was examined by scanning electron microscope (SEM). Through extracellular conductivity test and fluorescence microscope observation, it was found that carvacrol and thymol led to increase the permeability of target cells, the destruction of mitochondrial membrane and ROS accumulation. In vivo conditions, $1000 \mu \mathrm{g} / \mathrm{mL}$ carvacrol had the best protective and therapeutic effects on tomato gray mold $(77.98 \%$ and $28.04 \%$, respectively), and the protective effect was significantly higher than that of $400 \mu \mathrm{g} / \mathrm{mL}$ pyrimethanil $(43.15 \%)$. While the therapeutic and protective effects of $1000 \mu \mathrm{g} / \mathrm{mL}$ O. vulgare essential and thymol were comparable to agent control.

Conclusions: OVEO showed moderate antifungal activity, whereas its main components carvacrol and thymol have great application potential as natural fungicides or lead compounds for commercial fungicides in preventing and controlling plant diseases caused by B. cinerea.

Key words Origanum vulgare, carvacrol, thymol, Botrytis cinerea, antifungal activity, plant fungicide.

\section{Introduction}

Botrytis cinerea, a necrotrophic plant pathogenic fungus with broad hosts, can cause gray mold disease in many plants. The infected plants include many important agricultural, economic and horticultural crops, with a total of more than 1400 species such as grape, strawberry, tomato,

9 cucumber, orchid and other fruits, vegetables and flowers ( Fillinger \& Elad, 2016). It not only infects field crops, but also causes huge losses to the crops after harvesting (Romanazzi, \&

1 Feliziani, 2014). At present, benzimidazoles, dicarboximides, carbamates and antibiotics are the main fungicides to control this disease, whereas the resistance of $B$. cinerea to these fungicides 
has been widely reported (Leroux et al., 2002; Bardas et al., 2010; Liu et al., 2019). Most field investigations have demonstrated that $B$. cinerea has developed resistance to carbendazim, procymidone and diethofencarb in tomato and blueberry, and the point mutations, such as carbendazim-resistant phenotypes carried the point mutation E198A in the $\beta$-tubulin gene (tub) and procymidone-resistant phenotypes carried the point mutations $\mathrm{I} 365 \mathrm{~S}$ and a pair of point mutations Q369P and N373S in the amino acid sequence (Bos 1), have been identified (Adnan et

9 al., 2018; Sautua et al., 2019). Therefore, the control of gray mold is still facing great challenges. It is of great significance to explore new antifungal components for the integrated management of 1 gray mold.

Origanum species are herbaceous perennials distributed in different parts of the world including the Mediterranean, Central Asia, the Arabian Peninsula, Northern Africa, and Europe (Aligiannis et al., 2001; De Martino et al., 2009a). The genus Origanum consisits of 43 species and 18 hybrids (Tepe, Cakir \& Sihoglu Tepe, 2016). They are typically applied in food and cosmetics as a flavoring and aromatic agent (Gomez et al., 2018; Jan et al., 2020), and widely used in agriculture and traditional medicine due to its antimicrobial activity and antioxidant activities (Rodriguez-Garcia et al., 2015; Lu et al., 2018; Elshafie et al., 2015). Because of different 9 extraction techniques, plant parts or collected regions, different constituents were found in Origanum species, but most of them contain phenols, terpenes and their derivatives, such as $\gamma$ 1 terpinene, $\alpha$-thujene, $\beta$-myrcene, $\alpha$-terpinene, terpinen-4-ol, $\beta$-caryophyllene, linalool, limonene, thymol and carvacrol (Mamadalieva et al., 2017; Khan et al., 2019; Karpinski 2020; Ebadollahi, Ziaee \& Palla, 2020).

Previous studies have shown that the EOs of Origanum species (such as O. compactum, O. heracleoticum, O. majorana, O. onites, O. vulgare subsp. hirtum, and O. syriacum var. bevanii) exhibited antimicrobial activities against a variety of plant pathogenic fungi and bacteria (Table 1). In addition, they had excellent effects on the control of agricultural insect pests (Gong \& Ren, 2020; Pavela, 2012), stored product insects (Ebadollahi, Ziaee \& Palla, 2020) and acarids (Koc et 9 al., 2013; Shang et al., 2016). Interestingly, although many of Origanum species shared the same 
ingredients, it showed significant differences to the same microorganism (De Martino, De Feo \&

1 Nazzaro, 2009b; Mamadalieva et al., 2017; Moumni et al., 2020). This suggests that the antimicrobial effect of EOs may be related to the proportion of the main antimicrobial components or the synergistic with antagonistic effects of different chemical components (Wink 2015; Tepe, Cakir \& Sihoglu Tepe, 2016). So far, there is no evidence that Origanum species and its main components are harmful to humans and animals and have high phytotoxicity (Llana-Ruiz-Cabello et al., 2017; Elshafie et al., 2017).

Although extensive studies of the EOs of Origanum species have been conducted, however, O. vulgare populations from the Asian area have been poorly explored. In addition, many kinds of 9 EOs, such as Cinnamomum cassia (Ma et al., 2019), Litsea cubeba (Yang et al., 2010) and 9 Zanthoxylum leprieurii (Tanoh et al., 2020), etc, have also great potential in the control of plant

91 disease. Moreover, the researches on Origanum EOs and its main components against plant 9 pathogens mainly focus on the antimicrobial activities (De Martino et al., 2009a; Stefanakis et al., 9 2013), while the mechanism of antifungal action is still unclear and the actual application is also 9 necessary to be evaluated. Thus, this study was conducted to determine: (i) the antifungal activity 9 of 17 plant EOs against B. cinerea, (ii) the main components of OVEO by GC-MS, (iii) the 9 antifungal activities and mechanism of OVEO, carvacrol and thymol on B. cinerea in vitro, (iiii) 9 in vivo control effects of OVEO on B. cinerea, providing a foundation for the development and its $9 \quad$ utilization as a plant fungicide.

\section{Materials and methods}

Inhibitory activity of different plant EOs on mycelium growth of $B$. cinerea

11 Seventeen plant EOs were involved in the current study, namely Origanum vulgare, Cinnamomum cassia, Perilla frutescens, Saussurea costus, Mentha spicata, Litsea cubeba, Asarum sieboldii, Illicium verum, Foeniculum vulgare, Angelica dahurica, Curcuma zedoaria,

1 Mentha haplocalyx, Artemisia argyi, Eucalyptus globulus, Syzygium aromaticum, Acorus 1 tatarinowii and turpentine (mixture) EOs. All the EOs were purchased from Cedar pharmaceutical 1 Co., LTD, Jiangxi, China. Isolates of B. cinerea were prepared from tomato fruits (Luoyang, 
1 China) and deposited at the Key Laboratory of Creation \& Application of Novel Pesticides, Henan.

1 The preliminary antifungal activities of these EOs against $B$. cinerea were determined according

19 to the method described by Farzaneh et al. (2015). Emulsion of the EOs were prepared by sterile

11 water with $0.5 \%$ (v/v) acetone and Tween 80, blended with Potato Dextrose Agar ( PDA, $200 \mathrm{~g}$

111 extract of boiled potatoes, $20 \mathrm{~g}$ dextrose and $20 \mathrm{~g}$ agar powder in $1000 \mathrm{~mL}$ distilled water) at 40-

$1145^{\circ} \mathrm{C}$ to obtain final concentrations of 0 (control), 0.5 and $2 \mathrm{mg} / \mathrm{mL}$. A $5 \mathrm{~mm}$ mycelial disc from

11 young cultures of target fungi (3 days) was placed in treated sterile plates $(\mathrm{D}=7 \mathrm{~cm})$ after medium

11 solidification. The petri dishes were sealed with sealing film and cultured upside-down in dark at $1126.5^{\circ} \mathrm{C}$.

11 The mycelial growth was measured by a nonius using decussation way at 2, 4 and 6 days,

11 respectively. Three replicates per treatment were used in each experiment and the experiments

11 were performed three times Growth inhibition of each essential oil was computed by the formula 119 (1):

$$
\operatorname{Inhibition}(\%)=\left(D_{c}-D_{t}\right) /\left(D_{c}-0.5\right) \times 100
$$

11 Where $D_{c}$ is the colony diameter of the control group; and $D_{t}$ is the colony diameter of the

1 treatment groups with essential oil.

$1 \quad$ GC-MS analysis

1 The chemical compositions of OVEO was analyzed by GC-MS (Agilent-7890B, Agilent 1 technology co., LTD, USA) according to the method reported by Scalas et al. (2018). Chemicals 1 in OVEO were separated with HP-5 MS capillary column $(50 \mathrm{~m} \times 0.25 \mathrm{~mm} \times 0.25 \mu \mathrm{m})$, high-purity 1 Helium (99.999\%) as the carrier gas. The helium carrier gas rate was $1.0 \mathrm{~mL} / \mathrm{min}$ at a split ratio of $120.4: 1$, and the injection volume was $1.0 \mu \mathrm{L}$. The initial temperature was set at $60^{\circ} \mathrm{C}$ for $25 \mathrm{~min}$, 19 then gradually increased to $150^{\circ} \mathrm{C}$ at a rate of $1.2^{\circ} \mathrm{C} \cdot \mathrm{min}^{-1}$. Electron ionization was used as the ion 1 source, and the ionization energy was set at $70 \mathrm{eV}$. The quadrupole temperature was $150^{\circ} \mathrm{C}$, and

11 the ion source temperature was $230^{\circ} \mathrm{C}$. The sector mass analyzer was set to a range from 33 to 900 1 amu. Diluted samples (1/100, in acetone) at $1 \mu \mathrm{L}$ each were injected and mass spectra were 1 compared with the standard mass spectra from the NIST 2.2 database provided by the software of 
GC-MS system.

1 In vitro antifungal activities of OVEO, carvacrol and thymol against $B$. cinerea

19 below unless otherwise specified). The fungus were grown on a PDA plate for 5 days, and then

OVEO, carvacrol (purity 99\%) and thymol (purity 98.5\%, Sigma Aldrich, St. Louis, MO, USA) were dissolved in sterile water containing $0.1 \%(\mathrm{~V} / \mathrm{V})$ acetone and Tween 80 to prepare the stock solution at the concentration of $1000 \mu \mathrm{g} / \mathrm{mL}$ (the stock solution shall be used for dilution harvested using a $5 \mathrm{~mm}$ sterilized puncher along the edges of the colonies, and the fungal blocks 1 were placed in the center of PDA plates containing $0,2.5,5,10,15,20,40,50 \mu \mathrm{g} / \mathrm{mL}$ carvacrol and $0,2.5,5,10,20,40,60,80 \mu \mathrm{g} / \mathrm{mL}$ thymol. Cultures with $0.005 \%(0.008 \%)$ acetone and Tween 80 were used as the control, respectively. Incubation upside-down at $26.5^{\circ} \mathrm{C}$. The fungistatic effect was observed, and the colony diameter was measured and recorded when the diameter of the control was exceeded $7.5 \mathrm{~cm}$. Then, calculations were made for $B$. cinerea mycelium inhibition ability OVEO, carvacrol and thymol and regression equation and $\mathrm{EC}_{50}$ values by probability value analysis. Three replicates per treatment were carried out in each experiment and the experiments were performed three times.

Antifungal activity of OVEO, carvacrol and thymol on spore germination of $B$. cinerea

B. cinerea isolates were cultured on PDA plates at $20^{\circ} \mathrm{C}$ for 14 days. Then, the plates were injected with $5 \mathrm{ml}$ sterile water and gently scraped with a sterile swab and filtered through four layers of sterile cheesecloth to obtain spore suspension (Jing et al. 2018). The spore suspension concentration was adjusted to $10^{5} \sim 10^{6}$ spores $\mathrm{mL}^{-1}$ by using a hemocytometer and continuously adding sterile water. OVEO, carvacrol and thymol were blended with acetone and Tween 80 and sterile water, respectively, and the concentration was adjusted to 100, 200, 300, 400, 500, 600 $\mu \mathrm{g} / \mathrm{mL}$ at the same time, A $0.5 \mathrm{~mL}$ aliquot of conidium suspension of $B$. cinerea plus $0.5 \mathrm{~mL}$ liquid were added to a tube. Then, $60 \mu \mathrm{L}$ was transferred onto a double concave glass plate with pipette gun and placed in a wet sterile culture dish. Cultures with $0.03 \%$ acetone and Tween 80 were used 
1 as the control. The cultures were incubated at $28^{\circ} \mathrm{C}$. After incubating for 8 hours, spores of $B$.

11 cinerea were observed with a microscope (Nikon Eclipse Ti-S, Tokyo, Japan) at a

$1200 \times$ magnification. The spore germination percentage was calculated by counting germinated

1 spores among 200 spores. Three replicates per treatment were conducted in each experiment and

1 the experiments were performed three times.

1 Effects of carvacrol and thymol on fresh and dry mycelial weight of $B$. cinerea

The fresh and dry mycelial weight of the tested pathogen treated with carvacrol and thymol

1 were measured (Chen et al. 2014). According to the $\mathrm{EC}_{50}$ and $\mathrm{EC}_{90}$ of carvacrol and thymol, two

1 components were dissolved and diluted in sterile water with $0.1 \%$ acetone and Tween 80 , and

19 transferred into Erlenmeyer flasks with $25 \mathrm{~mL}$ of Potato Dextrose Broth (PDB, $200 \mathrm{~g}$ extract of

1 boiled potatoes, $20 \mathrm{~g}$ dextrose in $1000 \mathrm{~mL}$ distilled water) medium to obtain carvacrol

11 concentrations of 0 (control), $\mathrm{EC}_{50}(9.38 \mu \mathrm{g} / \mathrm{mL})$ and $\mathrm{EC}_{90}(43.49 \mu \mathrm{g} / \mathrm{mL})$ and thymol

1 concentrations of 0 (control), $\mathrm{EC}_{50}(21.32 \mu \mathrm{g} / \mathrm{mL})$ and $\mathrm{EC}_{90}(65.13 \mu \mathrm{g} / \mathrm{mL})$, respectively. The

1 pathogen was harvested along the edge of the colony (3 days) with a $5 \mathrm{~mm}$ sterilized punch, then

1 inoculated into each flaskand the flasks were incubated at $120 \mathrm{r} / \mathrm{min}$ shaking and $26.5^{\circ} \mathrm{C}$. The

1 mycelia groups were harvested on 3 days and strained off excess culture. The agar blocks were

1 removed with tweezers, and each mycelium groups were washed with sterile water at least three

1 times, and then filtered for 30 min to remove excess water on the surface. The fresh mycelia were

1 weighed and the dry mycelia as well after drying at $60^{\circ} \mathrm{C}$ for 12 hours. Each treatment consisted

19 of three replicates and the experiments were performed three times.

\section{Effect of carvacrol and thymol on the relative leakage of $B$. cinerea}

11 The permeability of the membrane was expressed in terms of relative extracellular conductivity and tested according to the method of Zhou et al. (2018) by using a Seven excellence multiparameter tester (METTLER TOLEDO Instrument Co., Ltd., Shanghai, China) with some

1 modifications. Carvacrol and thymol mother liquor were prepared with sterile water and $10 \%$ 1 dimethyl sulfoxide, and the final concentrations were $10,200,500 \mu \mathrm{g} / \mathrm{mL}$ and $70,200,500 \mu \mathrm{g} / \mathrm{mL}$, 1 respectively. Vinclozolin $(500 \mu \mathrm{g} / \mathrm{mL})$ was prepared with sterile water and $10 \%$ dimethyl sulfoxide 
Scanning electron microscopy and fluorescent microscopy

Carvacrol and thymol were dissolved and diluted in sterile water with acetone and Tween 80 . $1 \mathrm{~mL}$ of mixture and $9 \mathrm{~mL}$ PDA medium were mixed and poured into a $9 \mathrm{~mm}$ diameter Petri dishes. The final concentrations of $0(\mathrm{CK}), 25$ and $40 \mu \mathrm{g} / \mathrm{mL}$ of Carvacrol and thymol were obtained, respectively. Medium containing 0.004\% acetone and tween-80 was used as solvent control. The blocks of $B$. cinerea were inoculated on the medicated medium and cultured upside down at $26.5^{\circ} \mathrm{C}$ for 5 days. The effects of carvacrol and thymol on hyphal morphology were analysed using the modified method of Li et al. (2017). For SEM observation, PDA blocks about $95 \times 7 \mathrm{~mm}$ were cut from the edge of mycelium. Mycelium exposed to different treatments was fixed

as solvent. Fungal samples were collected 3 days after inoculation on PDA medium. Then the collected mycelium was inoculated in PDB and shaken at $120 \mathrm{rpm}$ and $26.5^{\circ} \mathrm{C}$ for 108 hours. Remove the agar blocks with tweezers, wash each mycelium groups with sterile water at least three times, and filter for $30 \mathrm{~min}$ to remove excess water on the surface. The mycelia $(0.1 \mathrm{~g})$ were separately put into the solution with the above series concentrations into glass tubes of $10 \mathrm{~mL}$, and 10\% dimethyl sulfoxide (DMSO) sterile distilled water was the solvent control. Vinclozolin containing 10\% DMSO was used as a positive control. Extracellular conductivity was measured at $0,10,40,140,220,360$ and $400 \mathrm{~min}$. Finally, the electrical conductivity was measured again after dead treatment (temperature $\geqslant 95^{\circ} \mathrm{C}, 25 \mathrm{~min}$ ). Three replicates per treatment were carried out in each experiment and the experiments were performed three times. The relative leakage was determined according to the formula (2):

$$
\text { Relative leakage }(\%)=\left(\mathrm{C}_{\mathrm{t}}-\mathrm{C}_{0}\right) / \mathrm{C}_{\mathrm{d}} \times 100
$$

Where $C_{t}$ is the conductivity of current time samples, $C_{0}$ is the conductivity of initial time ( 0 min) samples, and $\mathrm{C}_{\mathrm{d}}$ is the conductivity of dead treatment conductivity samples. 
1 series of ethanol concentrations $(30,50,70,80,90 \%$ and twice at $100 \%)$ for 15 min at each stage.

1 Samples were dried by $\mathrm{CO}_{2}$ critical point drier (CPD 030, Leica, Wetzlar, Germany), then gold

1 coated using a sputter coating machine (MC1000, Hitachi, Tokyo, Japan). All samples were

1 viewed in a SEM (Model SU8010-3400N, Hitachi) operating at $10 \mathrm{kV}$ at $2.5 \mathrm{k} \times$ magnification.

1 The fluorescence intensity of H2DCFDA dye under specific excitation wave is related to the 1 content of ROS, and the accumulation of ROS can be judged by the fluorescence intensity (Li et al. 2017). SYTOX Green is a fluorescent dye commonly used to study membrane integrity. It can pass through damaged membrane cells but cannot penetrate the complete cell membrane and emit

1 Green fluorescence. Rhodamine-123 is a cationic dye that can penetrate the cell membrane and is an indicator of mitochondrial transmembrane potential. Mitochondrial matrix fluorescence intensity weakened or disappeared in normal cells, and strong yellow-green fluorescence was released when mitochondrial membrane was destroyed (Tian et al. 2012).

Mycelium was observed by Nikon Eclipse Ti-S inverted fluorescence microscope (Eclipse TiS, Tokyo, Japan) and slightly modified (Jing et al. 2018). The fungal blocks were inoculated into $50 \mathrm{~mL}$ erlenmeyer flasks with PDB culture medium and the flasks were incubated at $120 \mathrm{r} / \mathrm{min}$ and $26.5^{\circ} \mathrm{C}$ for 2 days. Then the samples were incubated in PDB with the carvacrol and thymol

$9(100$ and $200 \mu \mathrm{g} / \mathrm{mL})$ for 12 hours, $0.1 \%$ acetone and Tween 80 , where sterile water was used as the blank control. The collected mycelia were stained with $1 \mu \mathrm{g} / \mathrm{mL}$ H2DCFDA, SYTOX Green

1 or Rhodamine 123 for $30 \mathrm{~min}$ at $4^{\circ} \mathrm{C}$ in darkness. After the dying, the mycelia were washed with phosphate buffered saline to remove the residual dye and then observed by fluorescence microscope. The views were randomly selected from each group, and all experiments were repeated six times and the experiments were performed three times.

Protective and therapeutic effects of OVEO, carvacrol and thymol on tomato gray mold caused by $B$. cinerea

Protective effect experiment: tomato fruits with same size and weight were selected and put in sterile plastic boxes (nine tomatoes in each box) with gauze at the bottom wetted with sterile

9 water to keep moisture. Tomatoes were sprayed with OVEO, carvacrol or thymol at 500 and 1000 
$\mu \mathrm{g} / \mathrm{mL}$, respectively. Pyrimethanil at $400 \mu \mathrm{g} / \mathrm{mL}$ was used as the standard control, and $0.1 \%$

1 acetone plus Tween 80 with sterile water was used as the solvent control. Sterile water was used as the blank control. Each box had one treatment, 9 repetitions for each treatment, and 3 fungal blocks for each repetition. After the liquid was dried, fungal blocks were placed on each tomato by acupuncture method and placed in the artificial climate box with humidity over $85 \%$ and temperature at $26.5^{\circ} \mathrm{C}$. After 48 hours, the diameter of the spot was measured and the control effect was calculated. Therapeutic effect experiment: Similar to protection, the above mentioned tomato fruits were inoculated with fungal blocks and cultured under the above conditions. After 24 hours, the above mentioned concentration solution was taken out and sprayed on the tomato fruits for

9 further culture. After 48 hours, the size of diseased spots was measured. The protective and therapeutic effects were calculated by the following formula (3):

$$
\text { Control efficacy }(\%)=\left(D_{c}-D_{t}\right) / D_{c} \times 100
$$

Where $\mathrm{D}_{\mathrm{c}}$ is the diameter of disease spots in the control group; and $\mathrm{D}_{t}$ is the spot diameter in the treatment group.

\section{Statistical analysis}

The statistical software SPSS (V 20.0; Chicago, IL, USA) was used for all data analyses. Data were analysed by Duncan's multiple range test at the level $\mathrm{P}<0.05$. Results

\section{Inhibitory activities of 17 plant EOs on mycelium growth of $B$. cinerea}

The antifungal activities of 17 plant EOs against B. cinerea are shown in Fig. 1. C. cassia, L.

9 cubeba and $O$. vulgare EOs completely inhibited the mycelial growth at the concentration of 0.5 $\mathrm{mg} / \mathrm{mL}$. In addition, the inhibition rate of $M$. spicata and S. aromaticum oils reached 91.70 and $187.55 \%$, respectively. At the concentration of $2 \mathrm{mg} / \mathrm{mL}$, the inhibition rate of $M$. haplocalyx, $I$. verum and $A$. sieboldii oils was $100,99.56$ and $82.53 \%$, respectively.

\section{GC-MS analysis of OVEO}

In total, 21 different chemical components are identified from the OVEO (Table 2; Fig. 2). Carvacrol (89.98\%) was found to be the major component, followed by $\beta$-caryophyllene $(3.34 \%)$, 
thymol (2.39\%), $\alpha$-humulene (1.38\%), and 1-methyl-2-propan-2-ylbenzene isopropyl benzene $(1.36 \%)$. In addition, the isomers carvacrol and thymol had adjacent peaks.

Antifungal activities of the OVEO, carvacrol and thymol against mycelial growth of

9 B. cinerea in vitro

The effects of the OVEO and its main components on B. cinerea are shown in Table 3. Among 1 the four main constituents, OVEO, carvacrol and thymol could significantly inhibit the mycelial growth of $B$. cinerea, where the effect increased with increasing the concentration, whereas $\beta$ caryophyllene showed no inhibitory effects on $B$. cinerea. The $\mathrm{EC}_{50}$ of carvacrol and thymol were 9.09 and $21.32 \mu \mathrm{g} / \mathrm{mL}$, respectively, lower than that of OVEO $(140.04 \mu \mathrm{g} / \mathrm{mL})$. Carvacrol and thymol as main antifungal components have been demonstrated, and were chosen for further study. Antifungal activities of OVEO, carvacrol and thymol on spore germination of $B$. cinerea

Carvacrol and thymol at all tested concentrations $(50-300 \mu \mathrm{g} / \mathrm{mL})$ result a significant low

9 germination of $B$. cinerea spores compared with the untreated ones (Fig. 3). Thymol at $250 \mu \mathrm{g} / \mathrm{mL}$ and carvacrol at $300 \mu \mathrm{g} / \mathrm{mL}$ can completely inhibit spore germination. However, the low 1 concentration of OVEO had no significant effect on the spore germination rate of $B$. cinerea. The spore germination was $80.03 \%$ at the concentration of $300 \mu \mathrm{g} / \mathrm{mL}$.

Effects of carvacrol and thymol on the mycelial morphology of $B$. cinerea

The mycelial morphology of $B$. cinerea treated with carvacrol and thymol at the concentration of $40 \mu \mathrm{g} / \mathrm{mL}$ is observed by SEM (Fig. 4). There were regular, uniform and complete mycelia with smooth surfaces in the control group, while the mycelia treated with carvacrol and thymol showed great morphological changes, including irregular growth of mycelium, formation of verrucous surface, shrinkage, collapse and hollowing of hyphae.

9 Effects of carvacrol and thymol on fresh and dry mycelium weight of $B$. cinereal

The mycelial growth of $B$. cinerea in PDB medium containing carvacrol and thymol for 3 
91 days is significantly inhibited (Fig. 5). The fresh and dry weights of the mycelia treated with $9 \quad$ carvacrol were 21.93 and $5.83 \mathrm{mg}, 8.30$ and $4.13 \mathrm{mg}$, respectively and had $\mathrm{EC}_{50}$ of $9.09 \mu \mathrm{g} / \mathrm{mL}$ 9 and $\mathrm{EC}_{90}$ of $40.62 \mu \mathrm{g} / \mathrm{mL}$. The inhibition rates of fresh and dry weights were $86.88,96.51 \%$ and $978.53,89.31 \%$, respectively. After being treated with thymol, the mycelial inhibitions of fresh and 9 dry weights were 78.06 and $98.23 \%, 69.94$ and $95.97 \%$, respectively where the $\mathrm{EC}_{50}$ reached 21.32 $9 \mu \mathrm{g} / \mathrm{mL}$ and $\mathrm{EC}_{90}$ reached $65.13 \mu \mathrm{g} / \mathrm{mL}$.

9 Effects of carvacrol and thymol on cell leakage of $B$. cinerea

9 A linear relative conductivity response with the increasing concentration of three reagents are

99 found in all treatments (Fig. 6). Compared with the blank control, the two treatments with carvacrol and thymol maintained a higher level of relative conductivity. When carvacrol and thymol were at

1 the lowest concentrations of $10 \mu \mathrm{g} / \mathrm{mL}$ and $70 \mu \mathrm{g} / \mathrm{mL}$, at the treatment time points of $10,40,140$, 220, 360 and $400 \mathrm{~min}$, the relative conductivity were $2.98,10.26,32.48,37.97,47.68,51.51 \%$ and $10.87,15.41,23.58,28.81,37.87,39.83 \%$, respectively. The relative conductivity was the same as of the positive control (vinclozolin) group at the same time. There was a more cell leakage when carvacrol and thymol increased to $200 \mu \mathrm{g} / \mathrm{mL}$ and $500 \mu \mathrm{g} / \mathrm{mL}$, compared with that of the vinclozolin.

Effects of carvacrol and thymol on reactive oxygen species accumulation, fungal membrane integrity and mitochondrial injury

9 The results of ROS accumulation, fungal membrane integrity and mitochondria damage 1 experiments are presented in Figs 7-9. Compared with the untreated hyphae, the treated hyphae 11 gave off strong green fluorescence, indicating there was a large amount of ROS accumulation in 1 the mycelium (Fig. 7). SYTOX Green penetrated the mycelium treated with carvacrol and thymol, 1 indicating that the integrity of the mycelial membrane was damaged (Fig. 8). Compared with 1 normal mitochondria, rhodamine 123, which entered the mitochondria from the outside, was re1 released after the membrane was damaged, emitting yellow-green fluorescence (Fig. 9).

$1 \quad$ Application of fungicides and disease assessment in vivo 
1 The results of in vivo conditions showed that OVEO, carvacrol and thymol have different

1 protective and therapeutic effects on tomato gray mold caused by $B$. cinerea (Table 4 ). At the

19 concentration of $500 \mu \mathrm{g} / \mathrm{mL}$, the protective and therapeutic effects of OVEO were significantly lower than pyrimethanil at $400 \mu \mathrm{g} / \mathrm{mL}$. Although the protective effect of carvacrol was comparable

1 to pyrimethanil, its therapeutic effect was lower. The therapeutic and protective effects of thymol were lower than that of the agent control treatment group. At the concentration of $1000 \mu \mathrm{g} / \mathrm{mL}$, OVEO and thymol had the same protective and therapeutic effects as $400 \mu \mathrm{g} / \mathrm{mL}$ pyrimethanil. The protective effect of carvacrol was significantly higher than pyrimethanil while the therapeutic effect was similar to that of the agent control. Among all the treatment groups, the protective effect of carvacrol $(77.98 \%)$ was the best.

\section{Discussion}

It has become a trend in recent years to find biosafe antimicrobial to reduce environmental

9 pollution and to cope with the resistance of traditional chemical agents. Many EOs and their components exhibit antifungal properties, but their high production cost and low concentration of

1 active ingredients limit their direct use in the control of plant and animal fungal diseases. Nevertheless, the use of plant EOs to control agricultural fungal diseases has been a hot research topic, such as Cymbopogon nardus and Syringa oblata EOs as a potential biocontrol agents to control black rot in cherry tomato (Chen et al. 2014) and brown spot in tobacco caused by Alternaria alternata (Jing et al. 2018), with great application potential in controlling important pathogen diseases of crops. Moreover, it has been found that $500 \mu \mathrm{L} / \mathrm{L}$ mint oil and its volatile vapor at $25^{\circ} \mathrm{C}$ could significantly inhibit the germination of conidia and the occurrence of disease in vivo (Xueuan et al., 2017). Eucalyptus staigeriana oil had the highest inhibitory activity against

9 B. cinerea spores and hyphae at $0.5 \mu \mathrm{L} / \mathrm{mL}$ (Pedrotti et al. 2019), and $\alpha$-pinene and $\beta$ caryophyllene from Cupressus sempervirens EO had high antifungal activity on $B$. cinerea when

1 used it in combination or alone (Rguez et al., 2018). In addition, previous studies have found that EOs as C. cassia (Wang et al., 2014), F. vulgare (Lopez-Reyes et al., 2013), I. verum (Lee et al., 2007), M. spicata (Benomari et al., 2018), O. vulgare (Abbaszadeh et al., 2014), and S. 
aromaticum (Gago et al., 2019) were all showed antifungal activities in different degrees against B. cinerea. To our knowledge, in this study, the mycelial growth inhibition of Litsea cubeba and Asarum sieboldii EOs on B. cinerea have not been reported.

Phenols with free - $\mathrm{OH}$ group can modify various amino acid residues of proteins, and interact with potential protein targets in fungal cells (Wink, 2015). At present, more than 150 compounds,

9 such as phenols, terpenes and their derivatives, have been reported from different regions $O$. vulgare, and most of them contain different contents of carvacrol and thymol (Hernandez-

1 Hernandez et al., 2014; Oliva Mde et al., 2015; Khan et al., 2019). In this study, GC/MS analysis showed that the main components of OVEO were carvacrol $(89.98 \%), \beta$-caryophyllene $(3.34 \%)$ and thymol (2.39\%). Previous studies have shown that carvacrol and thymol had strong inhibitory activity on a variety of pathogenic fungi and bacteria (Abbaszadeh et al., 2014; Elshafie et al., 2015; Taleb et al., 2018; Wang et al., 2019). In our experiment, carvacrol and thymol had a higher antifungal activity than OVEO on the mycelial growth, spore germination and the therapeutic and protective effects on tomato grey mould caused by B. cinerea in vitro, while their inhibitory effect was a concentration-dependent manner. Furthermore, we found that $\beta$-caryophyllene had no

9 significant fungicidal activity on $B$. cinerea. This result was also confirmed by other antibacterial activity test (Purkait et al., 2020). These results demonstrated that the carvacrol and thymol, as

1 phenol monomers, were the main fungicidal components of OVEO and the single component had a higher antifungal activity than the mixture. But whether there are synergistic effects between them and other components needs further study.

Protoplasmic membrane system, as a protective screen of cells, is necessary for the survival of fungus (Zhou et al., 2018). In this experiment, the destruction of cell membrane was confirmed by SEM and SYTOX Green fluorescence staining. Consistent with previous expectations and recent reports (Zhang et al. 2019), the results of SEM showed that the normal form of B. cinerea mycelia were damaged. After carvacrol and thymol treatment, the hypha appeared shrinkage, 9 collapse and disorganization compared with that in the control. In subsequent experiments, the fluorescent microscopy observation also confirmed that carvacrol and thymol destroyed mycelial 
1 membranes of $B$. cinerea in this study.

Previous studies have shown that essential oil could lead to the rupture and damage of fungal cell membrane (Yu et al., 2015) and abnormal transport function, nucleic acid and intracellular protein leakage, and abnormal metabolism, which is the possible mechanism of antifungal action of EOs (Chen et al., 2014; Jing et al., 2018). The relative leakage test showed that $200 \mu \mathrm{g} / \mathrm{mL}$ carvacrol and thymol could significantly increase the relative permeability of cells and $10 \mathrm{mg} / \mathrm{L}$ carvacrol and $70 \mathrm{mg} / \mathrm{L}$ thymol at the treatment time points of $(0 \sim 400 \mathrm{~min})$ were equivalent to that of vinclozolin. It was speculated that carvacrol and thymol as well as vinclozolin with known

9 mechanism of action can destroy the function of cell membrane (Choi, Lee \& Cho, 1996; Cabral \& Cabral, 1997) and cause leakage of enterocyte.

1 ROS (highly potent oxidants containing oxygen) encompasses oxygen free radicals and nonradical oxidants, can be interconverted from one to another by enzymatic and nonenzymatic mechanisms. A large amount of ROS can lead to oxidative damage of DNA base in cells and affect various redox reactions intra- and extracellular processes (Zorov et al., 2014), and play an important role in cell apoptosis (Wu et al., 2018). By using fluorescent dye DCFH-DA and flow cytometer, there was increased ROS intensity in Aspergillus flavus after the treatment of Anethum graveolens L. essential oil at different doses (Tian et al., 2012). Tea tree oil could lead to decreased activity of enzymes related to the tricarboxylic acid cycle and mitochondrial dysfunction as well

9 as sharply enhanced levels of ROS in B. cinerea (Li et al., 2017) In our experiment, the H2DCFDA

9 staining experiment showed that carvacrol and thymol significantly increased the content of ROS

91 in mycelia. This may indirectly lead to the death of fungal cells.

Mitochondria are important organelles that produce energy and biochemical reaction sites in

9 cells. Mitochondrial damage results in disruption of the respiratory chain and the tricarboxylic acid

9 (TCA) cycle pathway (Fernie, Carrari \& Sweetlove, 2004), induces ROS accumulation and 9 decreases intracellular productivity (Zorovet al., 2014). Hu et al. (2017) found that Curcuma longa 9 essential oil affected the mitochondrial ATPase and dehydrogenases activity (malate 9 dehydrogenase, succinate dehydrogenase) in A. flavus. Through RNA-seq, it was found that the 
9 expression levels of most genes in Fusarium oxysporum after treatment with thymol, including

99 glycolipid biosynthesis and glycolipid metabolism, were down-regulated while genes involved in antioxidant activity, chitin biosynthesis, and cell wall modification were up-regulated (Zhang, Ge

$1 \& Y u, 2018)$. In Rhodamine-123 staining experiment, the hyphae emitted strong green fluorescence after treatment with $200 \mu \mathrm{g} / \mathrm{mL}$ carvacrol and thymol. It was confirmed that mitochondria were damaged. There is no doubt that mitochondrial damage accelerates the rate of fungal cell apoptosis and leads to further accumulation of ROS. However, it was not clear whether the accumulation of ROS was caused by carvacrol and thymol or indirectly by the damage of mitochondria.

\section{Conclusion}

In conclusion, this study proved that a variety of plant EOs have fungicidal potential against B. cinerea, and found that carvacrol and thymol, as the main components of OVEO, can destroy 9 the mycelium morphology, increase cell membrane permeability, cause mitochondrial damaged 1 and ROS accumulation in B. cinerea. It was proved that carvacrol and thymol have high potential

11 in the control of gray mold caused by B. cinerea.

\section{Acknowledgements}

1 The study was financially supported by Innovation Scientists and Technicians Troop 1 Construction Projects of Henan Province (134100510009) and National Natural Science 1 Foundation of China (31371962).

\section{Compliance with ethical standards}

\section{Conflict of Interest}

1 The authors declare that they have no conflict of interest.

\section{Animal studies and human participants}

This article does not contain any studies with human participants or animal performed by any of 1 the authors.

\section{Informed consent}


Informed consent was obtained from all individual participants included in the study.

\section{Reference}

Abbaszadeh S, Sharifzadeh A, Shokri H, Khosravi, AR, Abbaszadeh A. 2014. Antifungal efficacy of thymol, carvacrol, eugenol and menthol as alternative agents to control the growth of food-relevant fungi. Journal de Mycologie Medicale 24(2):51-56 DOI 10.1016/j. mycmed.2014.01.063.

Adnan M, Hamada MS, Li GQ, Luo CX. 2018. Detection and molecular characterization of resistance to the dicarboximide and benzamide fungicides in Botrytis cinerea from tomato in Hubei Province, China. Plant Disease 102(7):1299-1306 DOI 10.1094/PDIS-10-17-1531-RE.

1 Aligiannis N, Kalpoutzakis E, Mitaku S, Chinou IB. 2001. Composition and Antimicrobial Activity of the Essential Oils of Two Origanum Species. Journal of Agricultural and Food Chemistry 49(9), 4168-4170, DOI $10.1021 / \mathrm{jf} 001494 \mathrm{~m}$

Altintas A, Tabanca N, Tyihak E, Ott PG, Moricz AM, Mincsovics E, Wedge, DE. 2013. Characterization of volatile constituents from Origanum onites and their antifungal and antibacterial activity. Journal of Aoac International 96(6): 1200-1208 DOI 10.5740/ jaoacint.sgealtintas.

Bardas GA, Veloukas T, Koutita O, Karaoglanidis GS. 2010. Multiple resistance of Botrytis cinerea from kiwifruit to SDHIs, QoIs and fungicides of other chemical groups. Pest Management Science 66(9):967-973 DOI:10.1002/ps.1968.

Benomari FZ, Andreu V, Kotarba J, Dib MEA, Bertrand C, Muselli A, Costa J, Djabou N. 2018. Essential oils from Algerian species of Mentha as new bio-control agents against phytopathogen strains. Environmental Science and Pollution Research 25(30): 29889-29900 DOI 10.1007/s11356-017-9991-4.

Cabral Smjes, Cabral JPS. 1997. Morphological and chemical alterations in Botrytis cinerea exposed to the dicarboximide fungicide vinclozolin. Canadian Journal of Microbiology 43(6): 552-560 DOI 10.1139/m97078.

Chen Q, Xu S, Wu T, Guo J, Sha S, Zheng X, Yu T. 2014. Effect of citronella essential oil on the inhibition

of postharvest Alternaria alternatain cherry tomato. Journal of the Science of Food and Agriculture 94(12): 24412447 DOI 10.1002/jsfa.6576.

9 Choi GJ, Lee HJ, Cho KY. 1996. Lipid peroxidation and membrane disruption by vinclozolin in dicarboximidesusceptible and resistant iolates of Botrytis cinerea. Pesticide Biochemistry and Physiology 55(1): 29-39 DOI 10.1006/pest.1996.0032.

Daferera DJ, Ziogas BN, Polissiou MG. 2003. The effectiveness of plant essential oils on the growth of Botrytis cinerea, Fusarium sp. and Clavibacter michiganensis subsp. michiganensis. Crop Protection 22(1): 39-44 DOI 10.1016/S0261-2194(02)00095-9.

De Martino L, De Feo V, Formisano C, Mignola E, Senatore F. 2009a. Chemical composition and antimicrobial activity of the essential oils from three chemotypes of Origanum vulgare L. ssp. hirtum (Link) Ietswaart growing wild in Campania (Southern Italy). Molecules 14(8):2735-2746 DOI 10.3390/molecules14082735.

De Martino L, De Feo V, Nazzaro F. 2009b. Chemical composition and in vitro antimicrobial and mutagenic activities of seven Lamiaceae essential oils. Molecules 14(10):4213-4230 DOI 10.3390/molecules14104213.

Della Pepa T, Elshafie HS, Capasso R, De Feo V, Camele I, Nazzaro F, Scognamiglio MR, Caputo L. 2019.

Antimicrobial and phytotoxic activity of Origanum heracleoticum and $O$. majorana essential oils growing in Cilento (Southern Italy). Molecules 24(14):2576 DOI 10.3390/molecules24142576.

Peer] reviewing PDF | (2020:01:45399:1:1:NEW 26 Jun 2020) 
Ebadollahi A, Ziaee M, Palla F. 2020. Essential oils extracted from different species of the Lamiaceae plant family as prospective bioagents against several detrimental pests. Molecules 25(7) DOI 10.3390/molecules25071556.

Fillinger S, Elad Y. 2016. Botrytis - the Fungus, the Pathogen and its Management in Agricultural Systems. Springer International Publishing DOI 10.1007/978-3-319-23371-0.

Elshafie HS, Armentano MF, Carmosino M, Bufo SA, De Feo V, Camele I. 2017. Cytotoxic activity of Origanum Vulgare L. on hepatocellular carcinoma cell line HepG2 and evaluation of its biological activity. Molecules 22(9) DOI 10.3390/molecules22091435.

Elshafie HS, Mancini E, Sakr S, De Martino L, Mattia CA, De Feo V, Camele I. 2015. Antifungal activity of some constituents of Origanum vulgare L. essential oil against postharvest disease of peach fruit. Journal of Medicinal Food 18(8):929-934, DOI:10.1089/jmf.2014.0167.

Farzaneh M, Kiani H, Sharifi R, Reisi M, Hadian J. 2015. Chemical composition and antifungal effects of three species of Satureja (S. hortensis, S. spicigera, and S. khuzistanica) essential oils on the main pathogens of strawberry fruit. Postharvest Biology and Technology 109:145-151. DOI 10.1016/j.postharvbio.2015.06.014.

Fernie AR, Carrari F, Sweetlove LJ. 2004. Respiratory metabolism: glycolysis, the TCA cycle and mitochondrial electron transport. Current Opinion in Plant Biology 7(3):254-261 DOI 10.1016/j.pbi.2004.03.007.

Gago CML, Artiga-Artigas M, Antunes MDC, Faleiro ML, Miguel MG, Martin-Belloso O. 2019. Effectiveness of nanoemulsions of clove and lemongrass essential oils and their major components against Escherichia coli and Botrytis cinerea. Journal of Food Science Technology 56(5):2721-2736 DOI 10.1007/s13197-01903762-1.

Gomez JV, Tarazona A, Mateo-Castro R, Gimeno-Adelantado JV, Jimenez M, Mateo EM. 2018. Selected plant essential oils and their main active components, a promising approach to inhibit aflatoxigenic fungi and aflatoxin production in food. Food Additives and Contaminants Part A-Chemistry Analysis Control Exposure \& Risk Assessment 35(8):1581-1595 DOI 10.1080/19440049.2017.1419287.

Gong X, Ren Y. 2020. Larvicidal and ovicidal activity of carvacrol, p-cymene, and gamma-terpinene from Origanum vulgare essential oil against the cotton bollworm, Helicoverpa armigera (Hubner). Environmental Science and Pollution Research 27(15):18708-18716 DOI 10.1007/s11356-020-08391-2.

Hernandez-Hernandez E, Regalado-Gonzalez C, Vazquez-Landaverde P, Guerrero-Legarreta I, GarciaAlmendarez, BE. 2014. Microencapsulation, chemical characterization, and antimicrobial activity of Mexican (Lippia graveolens H.B.K.) and European (Origanum vulgare L.) oregano essential oils. Scientific World Journal 2014: 641814 DOI 10.1155/2014/641814.

Hu Y, Zhang J, Kong W, Zhao G, Yang M. 2017. Mechanisms of antifungal and anti-aflatoxigenic properties of essential oil derived from turmeric (Curcuma longa L.) on Aspergillus flavus. Food Chemistry 220:1-8 DOI 10.1016/j.foodchem.2016.09.179.

Jan S, Rashid M, Abd Allah EF, Ahmad P. 2020. Biological Efficacy of Essential Oils and Plant Extracts of Cultivated and Wild Ecotypes of Origanum vulgare L. Biomed Research International 2020:8751718 DOI10 1155/2020/8751718.

Jing C, Zhao J, Han X, Huang R, Cai D, Zhang C. 2018. Essential oil of Syringa oblata Lindl. as a potential biocontrol agent against tobacco brown spot caused by Alternaria alternata. Crop Protection 104: 41-46, DOI 10.1016/j. cropro.2017.10.002.

Karpinski TM. 2020. Essential oils of Lamiaceae family plants as antifungals. Biomolecules 10(1):103 
DOI:10.3390/biom10010103.

Khan M, Khan ST, Khan M, Mousa AA, Mahmood A, Alkhathlan HZ. 2019. Chemical diversity in leaf and stem essential oils of Origanum vulgare L. and their effects on microbicidal activities. AMB Express 9(1):176 DOI 10.1186/s13568-019-0893-3.

Koc S, Oz E, Cinbilgel I, Aydin L, Cetin H. 2013. Acaricidal activity of Origanum bilgeri P.H. Davis (Lamiaceae)

Llana-Ruiz-Cabello M, Maisanaba S, Puerto M, Pichardo S, Jos A, Moyano R, Camean AM. 2017. A subchronic 90-day oral toxicity study of Origanum vulgare essential oil in rats. Food and Chemical Toxicology 101: 3647 DOI 10.1016/j.fct.2017.01.001.

Lopez-Reyes JG, Spadaro D, Prelle A, Garibaldi A, Gullino ML. 2013. Efficacy of plant essential oils on postharvest control of rots caused by fungi on different stone fruits in vivo. Journal of Food Protection 76(4): 631-639 DOI 10.4315/0362-028X.JFP-12-342. essential oil and its major component, carvacrol against adults Rhipicephalus turanicus (Acari: Ixodidae).

Lee SO, Park IK, Choi GJ, Lim HK, Jang KS, Cho KY, Shin SC, Kim JC. 2007. Fumigant activity of essential oils and components of Illicium verum and Schizonepeta tenuifolia against Botrytis cinerea and Colletotrichum gloeosporioides. Journal of Microbiology and Biotechnology 17(9): 1568-1572.

Leroux P, Fritz R, Debieu Dl, Albertini C, Lanen C, Bach J, Gredt M, Chapeland F. 2002. Mechanisms of resistance to fungicides in field strains of Botrytis cinerea. Pest Management Science 58(9): 876-888 DOI $10.1002 /$ ps.566.

Li Y, Shao X, Xu J, Wei Y, Xu F, Wang H. 2017. Tea tree oil exhibits antifungal activity against Botrytis cinerea by affecting mitochondria. Food Chemistry 234:62-67 DOI 10.1016/j.foodchem.2017.04.172.

Liu YH, Yuan SK, Hu XR, Zhang CQ. 2019. Shift of sensitivity in Botrytis cinerea to benzimidazole fungicides in strawberry greenhouse ascribing to the rising-lowering of E198A subpopulation and its visual, on-site monitoring by loop-mediated isothermal amplification. Scientific Reports 9:11644 DOI:10.1038/s41598019-48264-4.

Dai T, Murray CK, Wu MX. 2018. Bactericidal property of oregano oil against multidrug-resistant clinical isolates. Front Microbiol 9: 2329 DOI 10.3389/fmicb.2018.02329.

Ma YN, Chen CJ, Li Q, Wang W, Xu FR, Cheng YX, Dong X. 2019. Fungicidal activity of essential oils from Cinnamomum cassia against the Pathogenic Fungi of Panax notoginseng Diseases. Chemistry \& Biodiversity 16(11): e1900416 DOI 10.1002/cbdv.201900416.

Mamadalieva NZ, Akramov DK, Ovidi E, Tiezzi A, Nahar L, Azimova SS, Sarker SD. 2017. Aromatic medicinal plants of the Lamiaceae family from Uzbekistan: ethnopharmacology, essential oils composition, and biological activities. Medicines (Basel) 4(1) DOI:10.3390/medicines4010008.

Mancini E, Camele I, Elshafie HS, De Martino L, Pellegrino C, Grulova D, De Feo V. 2014. Chemical composition and biological activity of the essential oil of Origanum vulgare ssp. hirtum from different areas in the Southern Apennines (Italy). Chemistry \& Biodiversity 11(4): 639-651, DOI:10.1002/cbdv.201300326.

Moumni S, Elaissi A, Trabelsi A, Merghni A, Chraief I, Jelassi B, Chemli R, Ferchichi S. 2020. Correlation between chemical composition and antibacterial activity of some Lamiaceae species essential oils from Tunisia. BMC Complementary Medicine and Therapies 20(1): 103, DOI:10.1186/s12906-020-02888-6.

Oliva Mde L, Carezzano ME, Giuliano M, Daghero J, Zygadlo J, Bogino P, Giordano W, Demo M. 2015. Antimicrobial activity of essential oils of Thymus vulgaris and Origanum vulgare on phytopathogenic strains 
isolated from soybean. Plant Biology 17(3):758-765 DOI 10.1111/plb.12282.

Pavela R. 2012. Sublethal effects of some essential oils on the Cotton Leafworm Spodoptera littoralis (Boisduval). Journal of Essential Oil Bearing Plants 15(1):144-156 DOI 10.1080/0972060x.2012.10644030.

Pedrotti C, Marcon AR, Delamare APL, Echeverrigaray SL, Ribeiro R, Schwambach J. 2019. Alternative control of grape rots by essential oils of two Eucalyptus species. Journal of the Science of Food and Agriculture 99(14): 6552-6561 DOI 10.1002/jsfa.9936

1 Purkait S, Bhattacharya A, Bag A, Chattopadhyay RR. 2020. Evaluation of antibiofilm efficacy of essential oil components beta-caryophyllene, cinnamaldehyde and eugenol alone and in combination against biofilm formation and preformed biofilms of Listeria monocytogenes and Salmonella typhimurium. Letters in Applied Microbiology DOI 10.1111/lam.13308.

Rguez S, Djébali N, Ben Slimene I, Abid G, Hammemi M, Chenenaoui S, Bachkouel S, Daami-Remadi M, Ksouri R, Hamrouni-Sellami I. 2018. Cupressus sempervirens essential oils and their major compounds successfully control postharvest grey mould disease of tomato. Industrial Crops and Products 123:135-141 DOI 10.1016/j.indcrop.2018.06.060.

9 Rodriguez-Garcia I, Silva-Espinoza BA, Ortega-Ramirez LA, Leyva JM, Siddiqui MW, Cruz-Valenzuela MR, Gonzalez-Aguilar GA, Ayala-Zavala JF. 2015. Oregano essential oil as an antimicrobial and antioxidant additive in food products. Critical Reviews in Food Science and Nutrition 56(10):1717-1727 DOI 10.1080/10408398.2013.800832.

Romanazzi G, Feliziani E. 2014. Chapter 4 - Botrytis cinerea (Gray Mold). Postharvest Decay (pp. 131-146) San Diego: Academic Press DOI 10.1016/B978-0-12-411552-1.00004-1.

Santamarina MP, Rosello J, Sempere F, Gimenez S, Blazquez MA. 2015. Commercial Origanum compactum Benth. and Cinnamomum zeylanicum Blume essential oils against natural mycoflora in Valencia rice. Natural Product Research 29(23):2215-2218 DOI 10.1080/14786419.2014.1002406.

Sautua FJ, Baron C, Pérez-Hernández O, Carmona MA. 2019. First report of resistance to carbendazim and procymidone in Botrytis cinerea from strawberry, blueberry and tomato in Argentina. Crop Protection 125:UNSP 104879 DOI 10.1016/j.cropro.2019.104879.

1 Scalas D, Mandras N, Roana J, Tardugno R, Cuffini AM, Ghisetti V, Benvenuti S, Tullio V. 2018. Use of Pinus sylvestris L. (Pinaceae), Origanum vulgare L. (Lamiaceae), and Thymus vulgaris L. (Lamiaceae) essential oils and their main components to enhance itraconazole activity against azole susceptible/not-susceptible Cryptococcus neoformans strains. Complementary and Alternative Medicine 18(1):143 DOI 10.1186/s12906-018-2219-4.

Shang X, Wang Y, Zhou X, Guo X, Dong S, Wang D, Zhang J, Pan H, Zhang Y, Miao X. 2016. Acaricidal activity of oregano oil and its major component, carvacrol, thymol and p-cymene against Psoroptes cuniculi in vitro and in vivo. Veterinary Parasitology 226: 93-96 DOI 10.1016/j. vetpar.2016.07.001.

9 Soylu EM, Kurt S, Soylu S. 2010. In vitro and in vivo antifungal activities of the essential oils of various plants against tomato grey mould disease agent Botrytis cinerea. International Journal of Food Microbiology 143(3):183-189 DOI 10.1016/j.ijfoodmicro.2010.08.015.

Stefanakis MK, Touloupakis E, Anastasopoulos E, Ghanotakis D, Katerinopoulos HE, Makridis P. 2013. Antibacterial activity of essential oils from plants of the genus Origanum. Food Control 34(2):539-546 DOI 10.1016/j. foodcont.2013.05.024.

Taleb MH, Abdeltawab NF, Shamma RN, Abdelgayed SS, Mohamed SS, Farag MA, Ramadan MA. 2018. 
Origanum vulgare L. essential oil as a potential anti-acne topical nanoemulsion-in vitro and in vivo study. Molecules 23(9):2164 DOI 10.3390/molecules23092164.

Tanoh EA, Boue GB, Nea F, Genva M, Wognin EL, Ledoux A, Martin H, Tonzibo ZF, Frederich M, Fauconnier ML. 2020. Seasonal effect on the chemical composition, insecticidal properties and other biological activities of Zanthoxylum leprieurii Guill. \& Perr. essential oils. Foods, 9(5): DOI:10.3390/foods9050550.

Tepe B, Cakir A, Sihoglu Tepe A. 2016. Medicinal uses, phytochemistry, and pharmacology of Origanum onites (L.): a review. Chemistry \& Biodiversity 13(5):504-520, DOI:10.1002/cbdv.201500069.

Tian J, Ban X, Zeng H, He J, Chen Y, Wang Y. 2012. The mechanism of antifungal action of essential oil from dill (Anethum graveolens L.) on Aspergillus flavus. PLoS One, 7(1):e30147, DOI:10.1371/journal.pone.0030147.

Wang K, Jiang S, Yang Y, Fan L, Su F, Ye M. 2019. Synthesis and antifungal activity of carvacrol and thymol esters with heteroaromatic carboxylic acids. Natural Product Research 33(13):1924-1930 DOI 10.1080/14786419.2018.1480618.

Wang Y, Zhao R, Yu L, Zhang Y, He Y, Yao J. 2014. Evaluation of cinnamon essential oil microemulsion and its vapor phase for controlling postharvest gray mold of pears (Pyrus pyrifolia). Journal of Food Agriculture \& Environment 94(5):1000-1004 DOI 10.1002/jsfa.6360.

Wink M. 2015. Modes of action of herbal medicines and plant secondary metabolites. Medicines 2(3) 251-286 DOI 10.3390/medicines2030251.

Wu HY, Yang FL, Li LH, Rao, YK, Ju TC, Wong WT, Hsieh CY, Pivkin MV, Hua KF, Wu SH. 2018. Ergosterol peroxide from marine fungus Phoma sp. induces ROS-dependent apoptosis and autophagy in human lung adenocarcinoma cells. Scientific Reports 8(1):17956 DOI 10.1038/s41598-018-36411-2.

Xueuan R, Dandan S, Zhuo L, Qingjun K. 2017. Effect of mint oil against Botrytis cinerea on table grapes and its possible mechanism of action. European Journal of Plant Pathology 151(2): 321-328 DOI 10.1007/s10658017-1375-6.

9 Yang Y, Jiang J, Qimei L, Yan X, Zhao J, Yuan H, Qin Z, Wang M. 2010. The fungicidal terpenoids and essential oil from Litsea cubeba in Tibet. Molecules 15(10):7075-7082 DOI 10.3390/molecules15107075.

Yu D, Wang J, Shao X, Xu F, Wang H. 2015. Antifungal modes of action of tea tree oil and its two characteristic components against Botrytis cinerea. Journal of Applied Microbiology 119(5): 1253-1262 DOI 10.1111/jam.12939

Zandi-Sohani N, Ramezani L. 2015. Evaluation of five essential oils as botanical acaricides against the strawberry spider mite Tetranychus turkestani Ugarov and Nikolskii. International Biodeterioration \& Biodegradation 98:101-106 DOI 10.1016/j.ibiod.2014.12.007

Zhang J, Ma S, Du S, Chen S, Sun H. 2019. Antifungal activity of thymol and carvacrol against postharvest pathogens Botrytis cinerea. Journal of Food Science and Technology-Mysore 56(5): 2611-2620 DOI 10.1007/s13197-019-03747-0.

Zhang M, Ge J, Yu X. 2018. Transcriptome analysis reveals the mechanism of fungicidal of thymol against Fusarium oxysporum f. sp. niveum. Current Microbiology 75(4):410-419 DOI 10.1007/s00284-017-1396-6.

Zhou D, Wang Z, Li M, Xing M, Xian T, Tu K. 2018. Carvacrol and eugenol effectively inhibit Rhizopus stolonifer and control postharvest soft rot decay in peaches. Journal of Applied Microbiology 124(1):166-178 DOI 10.1111/jam.13612.

Zorov DB, Juhaszova M, Sollott SJ. 2014. Mitochondrial reactive oxygen species (ROS) and ROS-induced ROS release. Physiological Reviews 94(3):909-950 DOI 10.1152/physrev.00026.2013. 
Figure 1

Fig. 1 Inhibitory activity of 17 plant essential oils on the mycelial growth of $B$. cinerea (columns for each EOs from left to right denote 0.5 and $2.0 \mathrm{~g} / \mathrm{L}$ ). The fungal mycelial growth diameter of the control and treatments with different concentrations EOs were measured after $6 \mathrm{~d}$ of cultivation. The data were expressed as mean $\pm S D$ of three replicates. Values of different letters in the same column were significantly different at $P<0.05$. The $X$-axis refers to different EOs, and the Y-axis refers to the inhibition rate of mycelium growth.

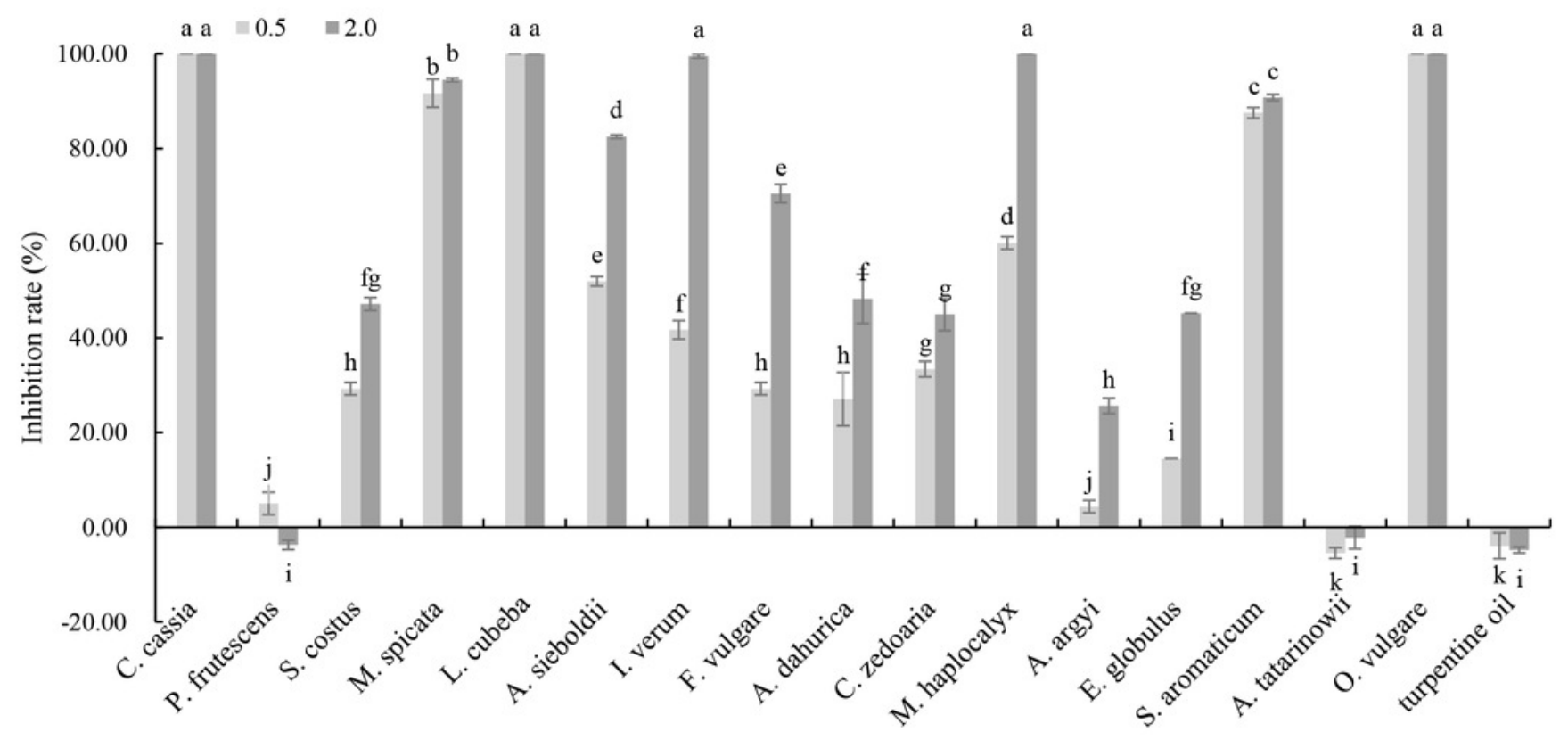


Figure 2

Fig. 2 GC-FID chromatogram of OVEO by an HP-5MS column.

The characterized peaks are numbered according to the serial numbers in Table 2 . 


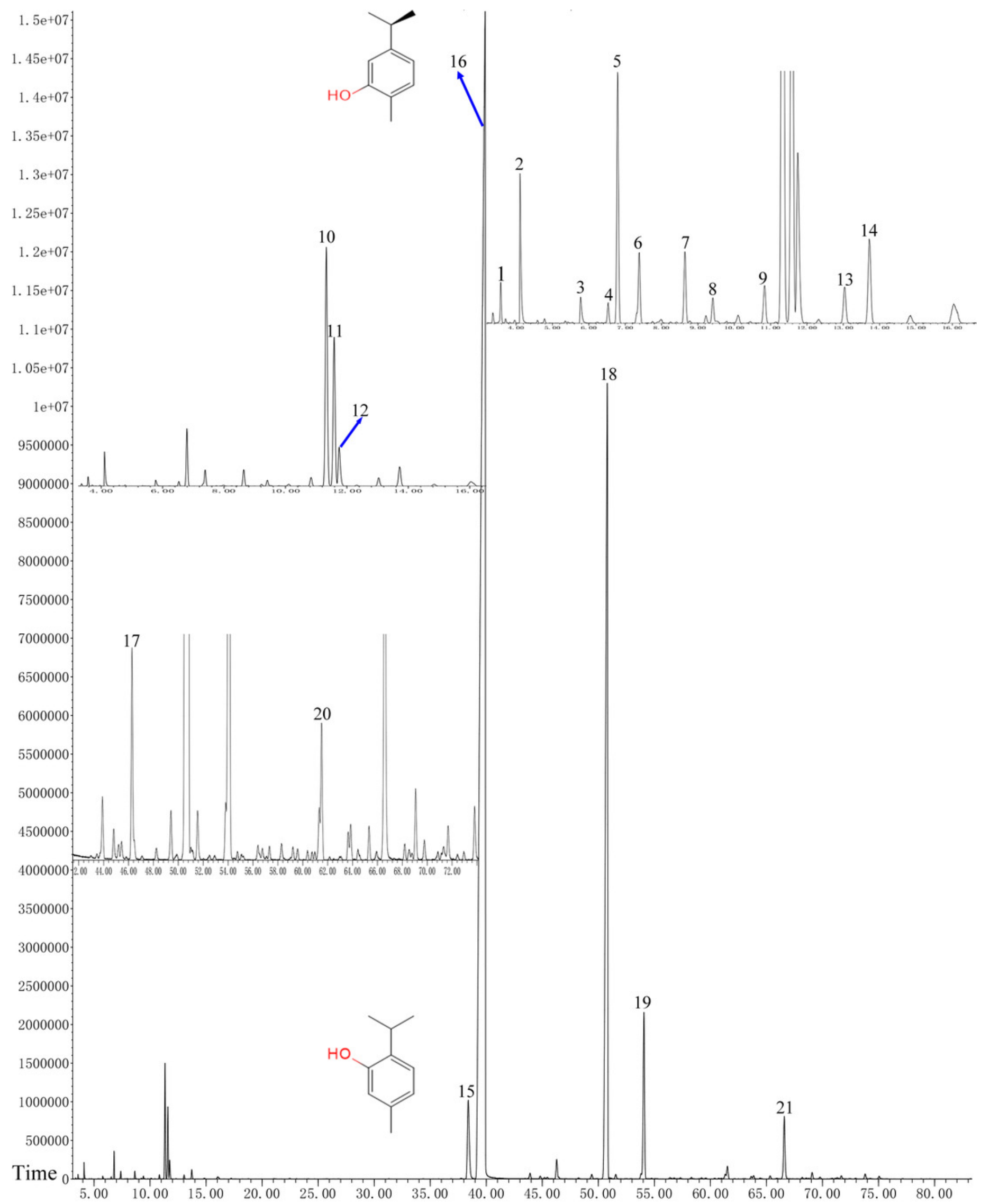




\section{Figure 3}

Fig. 3 Effects of OVEO, carvacrol and thymol on inhibition of spore germination of $B$. cinerea

(columns for each concentration from left to right denote carvacrol, thymol and OVEO). The fungal germination rate of the control and treatments with different concentrations of the reagents were measured after 8 hours of cultivation. The data were expressed as mean \pm SD of three replicates. Values of different letters in the same column were significantly different at $P<0.05$. The $\mathrm{X}$-axis refers to different concentrations, and the $\mathrm{Y}$-axis refers to the inhibition rate of spore germination.

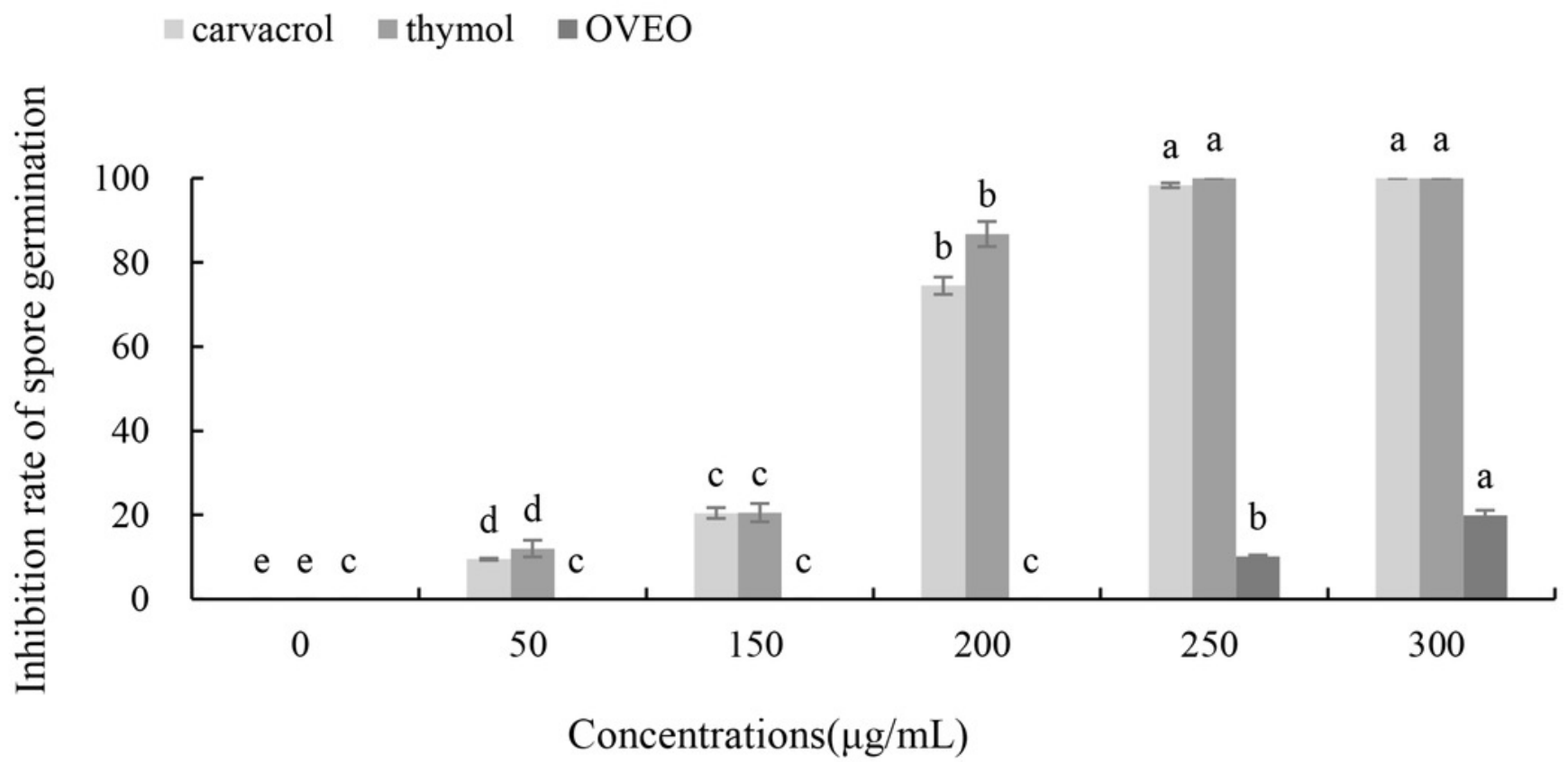




\section{Figure 4}

Fig. 4 Effects of carvacrol and thymol on the mycelial morphology of Botrytis cinerea.

Images obtained by scanning electron microscopy (Model SU8010-3400N; HITACH) with $2.5 \mathrm{k} \times$ magnifications at $10 \mathrm{kV}$. (A), healthy hyphae control. (B), hyphae treated with carvacrol at $40 \mu \mathrm{g} / \mathrm{mL}$. (C), hyphae treated with thymol at $40 \mu \mathrm{g} / \mathrm{mL}$.
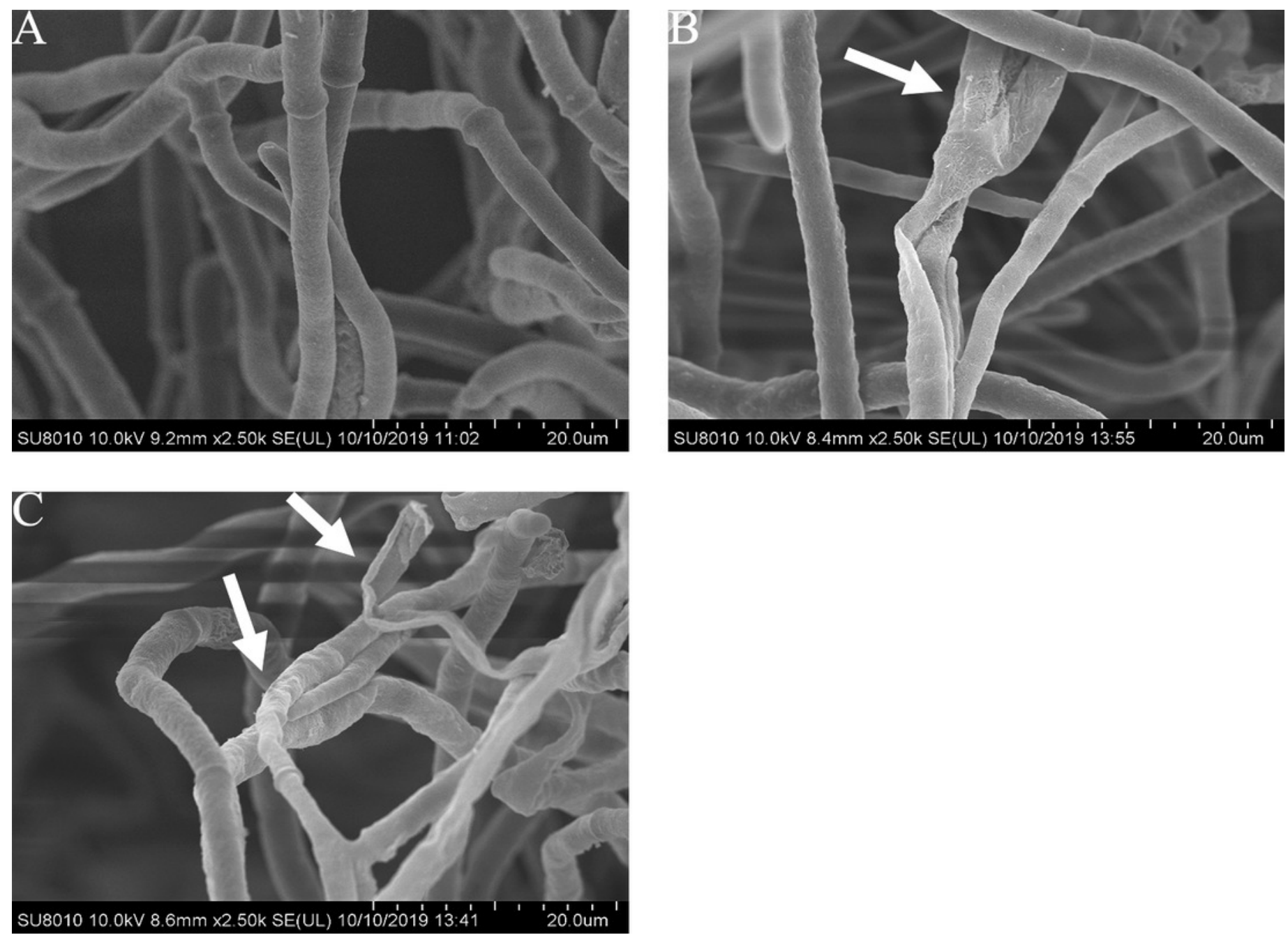


\section{Figure 5}

Fig. 5 Effects of carvacrol and thymol against mycelial biomass of $B$. cinerea.

Columns for each concentration from left to right denote (A) carvacrol fresh weight $A$, carvacrol dry weight $B$, thymol fresh weight $C$ and thymol dry weight $D$. (B) inhibition rate of carvacrol fresh weigh $A$, inhibition rate of carvacrol dry weight $B$, inhibition rate of thymol fresh weight $C$ and inhibition rate of thymol dry weight $D$. The fungal mycelial fresh and dry of the control and treatments with different concentrations reagents were measured after 3 days of shake cultivation. The data were expressed as mean $\pm S D$ of three replicates. Significant difference $(P<0.05)$ between the mean values was indicated by the letters above the histogram bars.
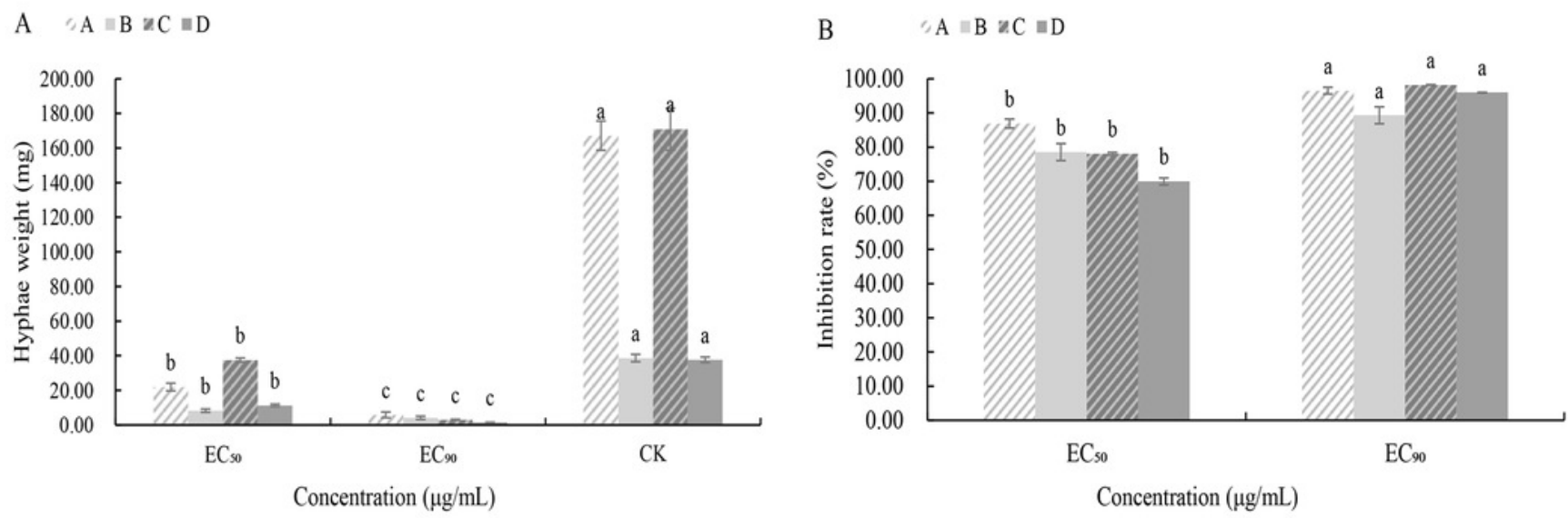
Figure 6

Fig. 6 Effect of different concentration of carvacrol (A) and thymol (B) on membrane permeability of $B$. cinerea.

Values are the mean \pm SD of three replicates. The $X$-axis refers to time, and the $Y$-axis refers to the relative extracellular conductivity of $B$. cinerea.
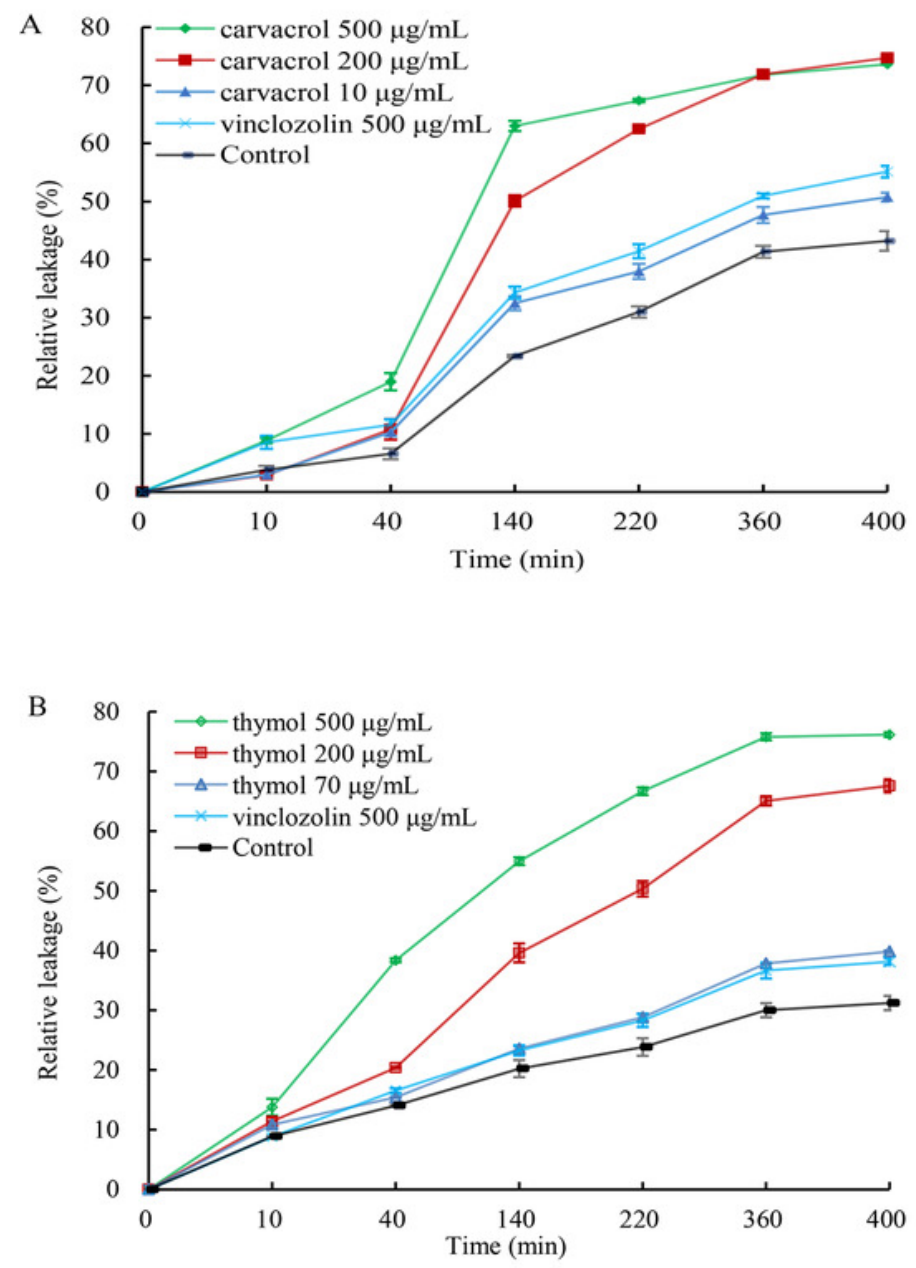


\section{Figure 7}

Fig. 7 Effects of carvacrol and thymol on ROS measured by fluorescence microscope

(Nikon Eclipse Ti-S, Japan) with 600x magnifications. First row: bright field. Second row:

$\mathrm{H}_{2}$ DCFDA . A and D untreated; $\mathrm{B}$ and $\mathrm{E}$ treated with carvacrol at $100 \mu \mathrm{g} / \mathrm{mL} ; \mathrm{C}$ and $\mathrm{F}$ treated with thymol at $100 \mu \mathrm{g} / \mathrm{mL}$.
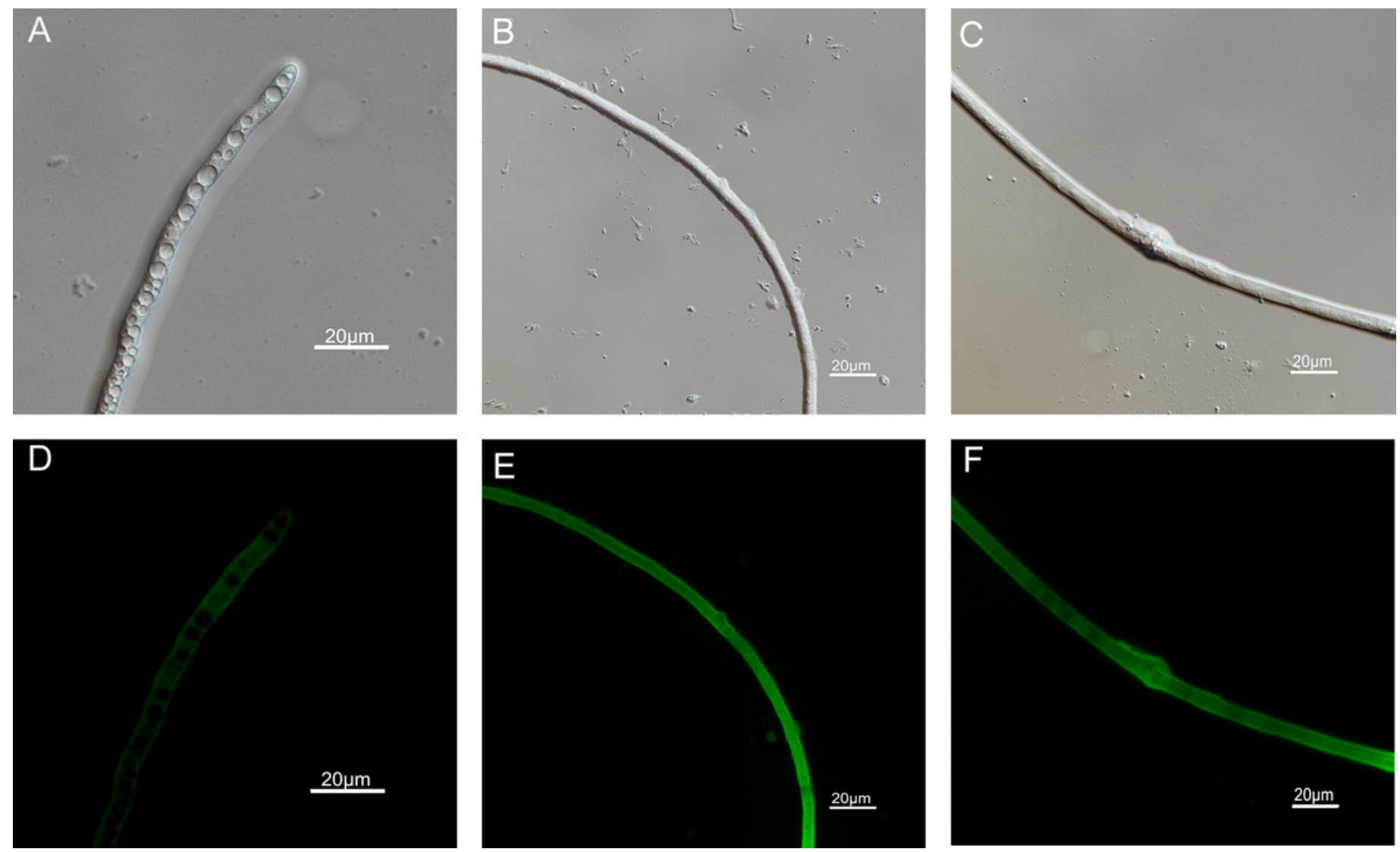


\section{Figure 8}

Fig. 8 Effects of carvacrol and thymol on plasma membrane integrity measured by fluorescence microscope

(Nikon Eclipse Ti-S, Japan) with 600x magnifications. First row: bright field. Second row: SYTOX Green . A and D untreated ; B and E treated with carvacrol at $200 \mu \mathrm{g} / \mathrm{mL} ; \mathrm{C}$ and F treated with thymol at $200 \mu \mathrm{g} / \mathrm{mL}$.
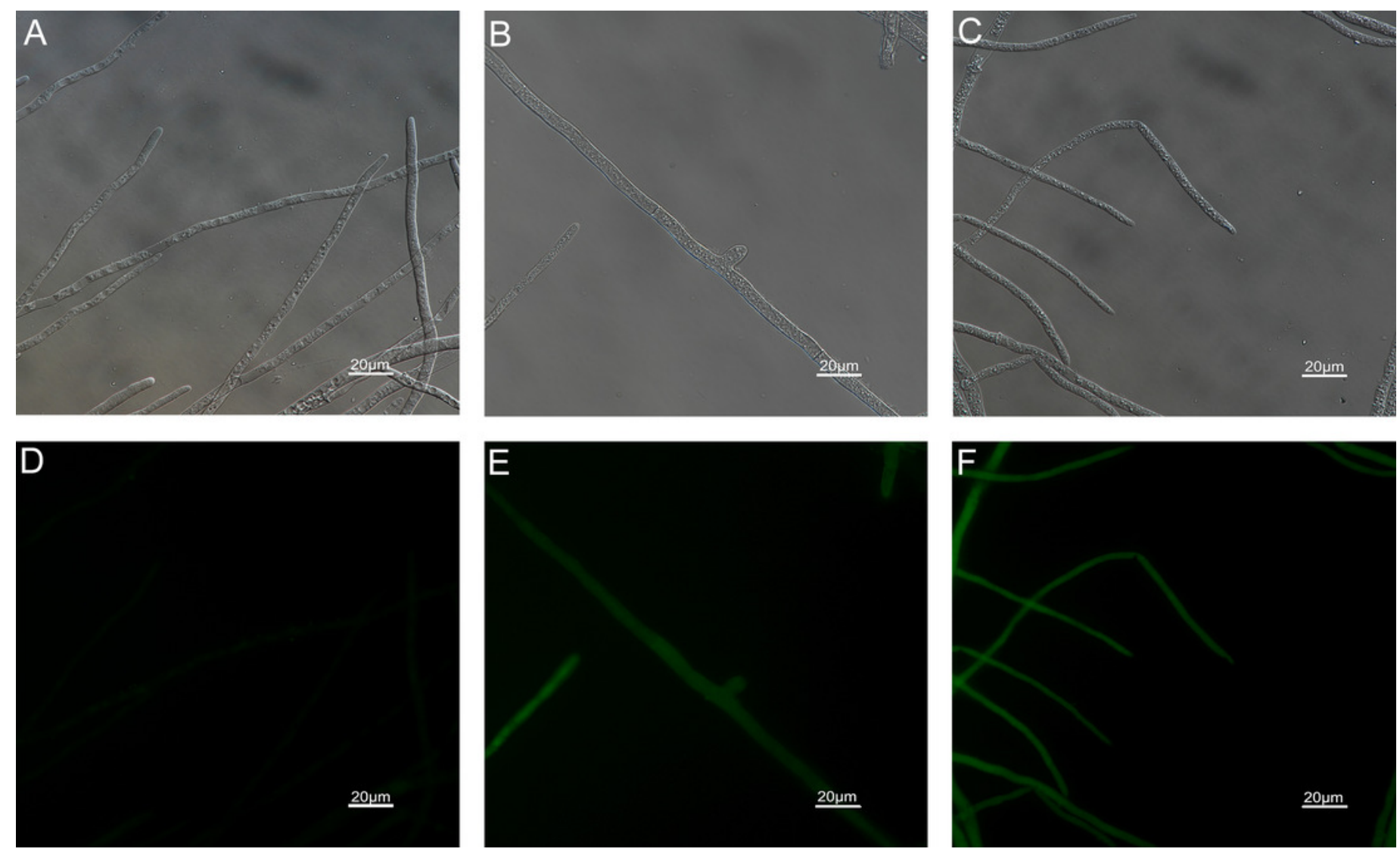


\section{Figure 9}

Fig. 9 Effects of carvacrol and thymol on mitochondrial integrity measured by fluorescence microscope

(Nikon Eclipse Ti-S, Japan) with 200x magnifications. First row: bright field. Second row:

Rhodamine 123 . A and D untreated; B and E treated with carvacrol at $200 \mu \mathrm{g} / \mathrm{mL} ; \mathrm{C}$ and $\mathrm{F}$ treated with thymol at $200 \mu \mathrm{g} / \mathrm{mL}$.
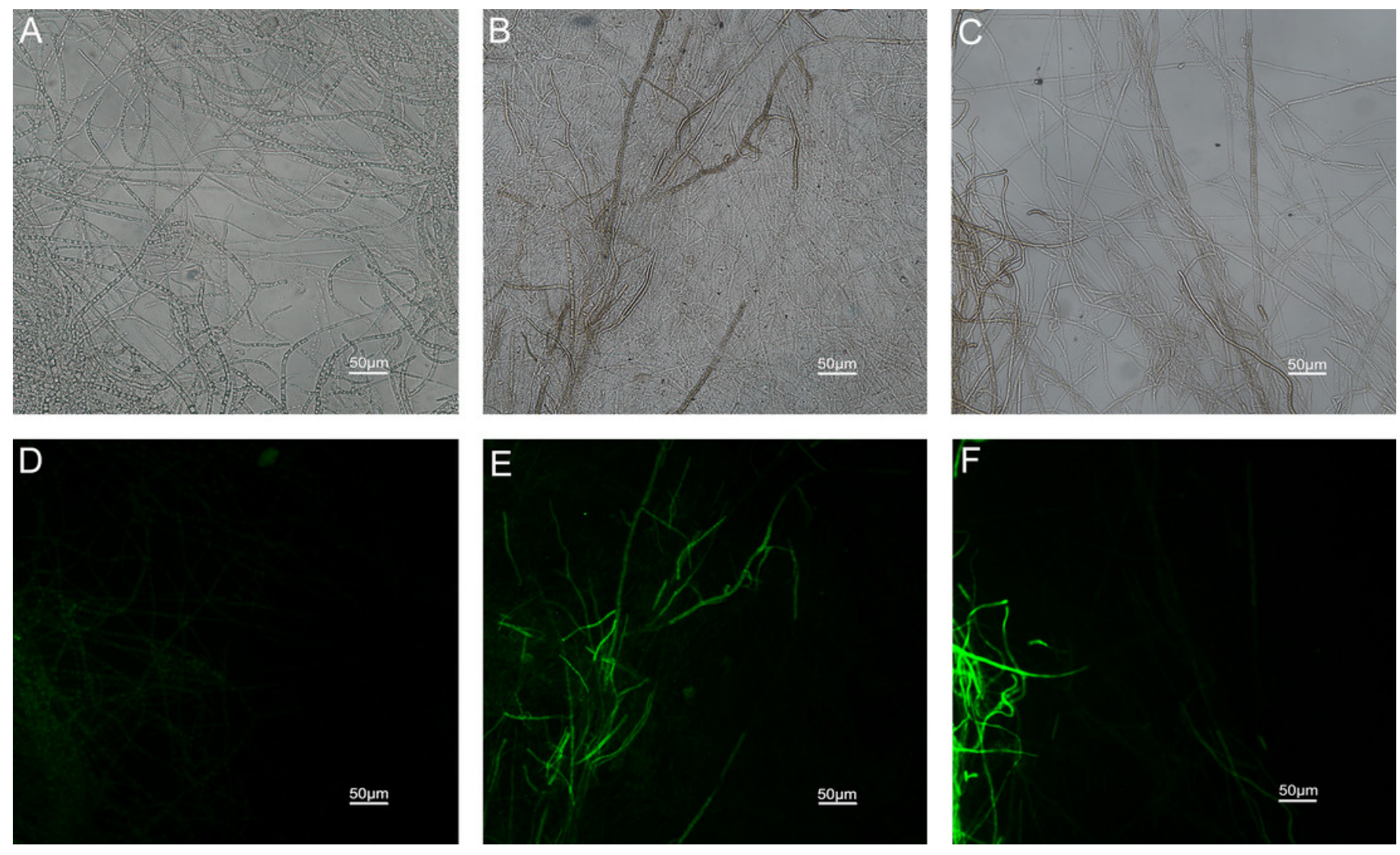


\section{Table 1 (on next page)}

Table 1. A list of reports indicating antimicrobial effects of EOs isolated from the Origanum genus. 


\begin{tabular}{|c|c|c|c|c|}
\hline Origanum species & Chemotype & Antifungal & Antibacterial & Ref. \\
\hline O. vulgare & $\begin{array}{l}\text { Carvacrol, } \\
\text { thymol }\end{array}$ & $\begin{array}{l}\text { Botrytis cinerea, } \\
\text { Fusarium solani var. } \\
\text { coeruleum }\end{array}$ & $\begin{array}{l}\text { Clavibacter michiganensis } \\
\text { subsp. Michiganensis, } \\
\text { Propionibacterium acnes } \\
\text { Staphylococcus epidermidis }\end{array}$ & $\begin{array}{l}\text { (Daferera, } \\
\text { Ziogas \& } \\
\text { Polissiou, } \\
\text { 2003; Taleb } \\
\text { et al., 2018) }\end{array}$ \\
\hline $\begin{array}{l}\text { O.vulgare. Subsp. } \\
\text { hirtum }\end{array}$ & $\begin{array}{l}\text { Carvacrol, } \\
\text { thymol }\end{array}$ & $\begin{array}{l}\text { Monilinia laxa, } \\
\text { Monilinia fructigena, } \\
\text { Monilinia fructicola }\end{array}$ & $\begin{array}{l}\text { Escherichia coli, } \\
\text { Listonella anguillarum, } \\
\text { Vibrio alginolyticus, } \\
\text { Vibrio splendidus, } \\
\text { Vibrio sp., } \\
\text { Saccharomyces cerevisiae }\end{array}$ & $\begin{array}{l}\text { (Stefanakis et } \\
\text { al., 2013; } \\
\text { Elshafie et } \\
\text { al., 2015) }\end{array}$ \\
\hline O. compactum & $\begin{array}{l}\text { Carvacrol, } \\
\text { thymol }\end{array}$ & $\begin{array}{l}\text { Alternaria alternata, } \\
\text { Bipolaris oryzae, } \\
\text { Fusarium graminearum, } \\
\text { Fusarium equiseti, } \\
\text { Fusarium verticillioides }\end{array}$ & & $\begin{array}{l}\text { (Santamarina } \\
\text { et al., 2015) }\end{array}$ \\
\hline O. heracleoticum & Carvacrol & $\begin{array}{l}\text { Aspergillus niger, Botrytis } \\
\text { cinerea, Monilinia } \\
\text { fructicola, } \\
\text { Penicillium expansum }\end{array}$ & $\begin{array}{l}\text { Bacillus megaterium, } \\
\text { Clavibacter michiganensis, } \\
\text { Xanthomonas campestris, } \\
\text { Pseudomonas fluorescens, } \\
\text { Pseudomonas syringae pv. } \\
\text { phaseolicola }\end{array}$ & $\begin{array}{l}\text { (Della Pepa } \\
\text { et al., 2019) }\end{array}$ \\
\hline O. majorana & $\begin{array}{l}\text { terpinen-4-ol, } \\
\delta \text {-2-carene, } \\
\Upsilon \text {-Terpinene, } \\
\text { carvacrol }\end{array}$ & $\begin{array}{l}\text { Aspergillus niger, } \\
\text { Monilinia fructicola, } \\
\text { Penicillium expansum }\end{array}$ & $\begin{array}{l}\text { Bacillus megaterium, } \\
\text { Bacillus subtilis, } \\
\text { Clavibacter michiganensis, } \\
\text { Escherichia coli, } \\
\text { Listonella anguillarum, } \\
\text { Pseudomonas aeruginosa, } \\
\text { Pseudomonas fluorescens, } \\
\text { Pseudomonas syringae pv. } \\
\text { Phaseolicola, } \\
\text { Saccharomyces cerevisiae, } \\
\text { Salmonella enterica, } \\
\text { Staphylococcus aureus, } \\
\text { Vibrio splendidus, } \\
\text { Vibrio alginolyticus, } \\
\text { Vibrio sp., } \\
\text { Xanthomonas campestris }\end{array}$ & $\begin{array}{l}\text { (Della Pepa } \\
\text { et al., 2019; } \\
\text { Moumni et } \\
\text { al., 2020; } \\
\text { Stefanakis et } \\
\text { al., 2013) }\end{array}$ \\
\hline O. onites & $\begin{array}{l}\text { Carvacrol, } \\
\text { thymol }\end{array}$ & $\begin{array}{l}\text { Botrytis cinerea, } \\
\text { Colletotrichum acutatum, }\end{array}$ & $\begin{array}{l}\text { Bacillus subtilis, } \\
\text { Escherichia coli, }\end{array}$ & $\begin{array}{l}\text { (Altintas et } \\
\text { al., 2013; }\end{array}$ \\
\hline
\end{tabular}


Colletotrichum fragariae,

Colletotrichumg

loeosporioides,

Phomopsis obscurans
Listonella anguillarum,

Vibrio splendidus,

Vibrio alginolyticus,

Vibrio sp.,

Saccharomyces cerevisiae

1

Peer) reviewing PDF | (2020:01:45399:1:1:NEW 26 Jun 2020) 
Table 2 (on next page)

Table 2 Chemical components of the OVEO determined by GC-MS.

${ }^{\text {a }}$ Relative proportions of EO constituents. 


\begin{tabular}{|c|c|c|c|c|}
\hline No. & $\begin{array}{l}\text { Retention time } \\
\quad(\min )\end{array}$ & Compound & $\begin{array}{l}\text { Molecular } \\
\text { formula }\end{array}$ & $\operatorname{Area}(\%)^{\mathrm{a}}$ \\
\hline 1. & 3.574 & butyl acetate & $\mathrm{C}_{6} \mathrm{H}_{12} \mathrm{O}_{2}$ & 0.04 \\
\hline 2. & 4.106 & diacetone alcohol & $\mathrm{C}_{6} \mathrm{H}_{12} \mathrm{O}_{2}$ & 0.16 \\
\hline 3. & 5.777 & 2-butoxyethanol & $\mathrm{C}_{6} \mathrm{H}_{14} \mathrm{O}_{2}$ & 0.03 \\
\hline 4. & 6.532 & $\alpha$-thujene & $\mathrm{C}_{10} \mathrm{H}_{16}$ & 0.01 \\
\hline 5. & 6.789 & $\alpha$-Pinene & $\mathrm{C}_{10} \mathrm{H}_{16}$ & 0.07 \\
\hline 6 & 7.384 & camphene & $\mathrm{C}_{10} \mathrm{H}_{16}$ & 0.02 \\
\hline 7 & 8.649 & $\beta$-pinene & $\mathrm{C}_{10} \mathrm{H}_{16}$ & 0.21 \\
\hline 8 & 9.404 & $\beta$-myrcene & $\mathrm{C}_{10} \mathrm{H}_{16}$ & 0.07 \\
\hline 9 & 10.835 & $\alpha$-terpinene & $\mathrm{C}_{10} \mathrm{H}_{16}$ & 0.04 \\
\hline 10 & 11.338 & 1-methyl-2-propan-2-ylbenzene & $\mathrm{C}_{10} \mathrm{H}_{14}$ & 1.36 \\
\hline 11 & 11.590 & (4R)-limonene & $\mathrm{C}_{10} \mathrm{H}_{16}$ & 0.34 \\
\hline 12 & 11.756 & 1,8-cineole & $\mathrm{C}_{10} \mathrm{H}_{18} \mathrm{O}$ & 0.12 \\
\hline 13 & 13.038 & (E)- $\beta$-ocimene & $\mathrm{C}_{10} \mathrm{H}_{16}$ & 0.02 \\
\hline 14 & 13.713 & $\gamma$-terpinene & $\mathrm{C}_{10} \mathrm{H}_{16}$ & 0.10 \\
\hline 15 & 38.381 & thymol & $\mathrm{C}_{10} \mathrm{H}_{14} \mathrm{O}$ & 2.39 \\
\hline 16 & 39.903 & carvacrol & $\mathrm{C}_{10} \mathrm{H}_{14} \mathrm{O}$ & 89.98 \\
\hline 17 & 46.283 & $\alpha$-copaene & $\mathrm{C}_{15} \mathrm{H}_{24}$ & 0.08 \\
\hline 18 & 50.803 & (-)- $\beta$-caryophyllene & $\mathrm{C}_{15} \mathrm{H}_{24}$ & 3.34 \\
\hline 19 & 54.071 & (1E,4E,8E)- $\alpha$-humulene & $\mathrm{C}_{15} \mathrm{H}_{24}$ & 1.38 \\
\hline 20 & 61.521 & $\beta$-cadinene & $\mathrm{C}_{15} \mathrm{H}_{24}$ & 0.18 \\
\hline 21 & 66.596 & (-)-Caryophyllene oxide & $\mathrm{C}_{15} \mathrm{H}_{24} \mathrm{O}$ & 0.07 \\
\hline
\end{tabular}

1 


\section{Table 3 (on next page)}

Table 3 Toxicities of OVEO, carvacrol and thymol against mycelial growth of $B$. cinerea 


\begin{tabular}{ccccc}
\hline Essential oil & Regression equation & $r$ & $\mathrm{EC}_{50}(95 \% \mathrm{FL})(\mu \mathrm{g} / \mathrm{mL})$ & $X^{2}$ \\
\hline OVEO & $Y=1.7615 X+1.2193$ & 0.9740 & 140.04 & $(58.07 \sim 337.72)$ \\
carvacrol & $Y=1.9704 X+3.1117$ & 0.9931 & $9.09(3.96 \sim 20.85)$ & 3.72 \\
thymol & $Y=2.6426 X+1.4884$ & 0.9974 & $21.32(9.95 \sim 45.68)$ & 3.99 \\
$\beta$-caryophyllene & - & - & - & - \\
\hline
\end{tabular}

1 


\section{Table 4 (on next page)}

Table 4 Protective and therapeutic effects of OVEO, carvacrol and thymol against tomato gray mold cuased by $B$. cinerea

Values are expressed as the means \pm SE of nine replicates. Different letters in each column indicate statistically significant differences $(P<0.05)$. 
1 Table 4 Protective and therapeutic effects of OVEO, carvacrol and thymol against tomato gray

2 mold cuased by $B$. cinerea

\begin{tabular}{|c|c|c|c|c|c|}
\hline \multirow{2}{*}{ Reagents } & \multirow{2}{*}{$\begin{array}{l}\text { Concentrati } \\
\text { on } \\
(\mu \mathrm{g} / \mathrm{mL})\end{array}$} & \multicolumn{2}{|c|}{ Protective effects } & \multicolumn{2}{|c|}{ Therapeutic effects } \\
\hline & & $\begin{array}{l}\text { Patch diameter } \\
\qquad(\mathrm{cm})\end{array}$ & $\begin{array}{c}\text { Relative } \\
\text { efficacy (\%) }\end{array}$ & $\begin{array}{l}\text { Patch diameter } \\
(\mathrm{cm})\end{array}$ & $\begin{array}{c}\text { Relative } \\
\text { efficacy (\%) }\end{array}$ \\
\hline \multirow{2}{*}{$\begin{array}{c}\text { O.vulgare } \\
\text { essential } \\
\text { oil }\end{array}$} & 500 & $2.01 \pm 0.20 \mathrm{~b}$ & $18.88 \mathrm{~d}$ & $2.49 \pm 0.22 \mathrm{~b}$ & $9.41 \mathrm{c}$ \\
\hline & 1000 & $1.52 \pm 0.23 \mathrm{~cd}$ & $38.50 \mathrm{~b}$ & $2.21 \pm 0.24 \mathrm{~cd}$ & $19.70 \mathrm{ab}$ \\
\hline \multirow{2}{*}{ Carvacrol } & 500 & $1.50 \pm 0.23 \mathrm{~cd}$ & $39.40 \mathrm{~b}$ & $2.39 \pm 0.28 b c$ & $13.32 \mathrm{bc}$ \\
\hline & 1000 & $0.54 \pm 0.21 \mathrm{e}$ & $77.98 \mathrm{a}$ & $1.98 \pm 0.44 \mathrm{~d}$ & $28.04 \mathrm{a}$ \\
\hline \multirow{2}{*}{ Thymol } & 500 & $1.75 \pm 0.23 \mathrm{c}$ & $29.29 \mathrm{c}$ & $2.47 \pm 0.28 \mathrm{bc}$ & $10.36 \mathrm{bc}$ \\
\hline & 1000 & $1.34 \pm 0.27 \mathrm{~d}$ & $45.92 \mathrm{~b}$ & $2.02 \pm 0.19 \mathrm{~d}$ & $26.50 \mathrm{a}$ \\
\hline $\begin{array}{c}\text { pyrimethan } \\
: 1\end{array}$ & 400 & $1.41 \pm 0.38 \mathrm{~d}$ & $43.15 \mathrm{~b}$ & $2.02 \pm 0.26 \mathrm{~d}$ & $26.56 \mathrm{a}$ \\
\hline Control & 0 & $2.47 \pm 0.22 \mathrm{a}$ & $0.00 \mathrm{e}$ & $2.75 \pm 0.21 \mathrm{a}$ & $0.00 \mathrm{e}$ \\
\hline
\end{tabular}

3 Values are expressed as the means $\pm \mathrm{SE}$ of nine replicates. Different letters in each column indicate

4 statistically significant differences $(P<0.05)$. 